\title{
Profiling aerosol optical, microphysical and hygroscopic properties in ambient conditions by combining in situ and remote sensing
}

\author{
Alexandra Tsekeri ${ }^{1}$, Vassilis Amiridis ${ }^{1}$, Franco Marenco $^{2}$, Athanasios Nenes ${ }^{3,4,5}$, Eleni Marinou ${ }^{1,6}$, Stavros Solomos $^{1}$, \\ Phil Rosenberg $^{7}$, Jamie Trembath ${ }^{8}$, Graeme J. Nott ${ }^{8}$, James Allan $^{9,10}$, Michael Le Breton ${ }^{9}$, Asan Bacak ${ }^{9}$, Hugh Coe $^{9}$, \\ Carl Percival $^{9}$, and Nikolaos Mihalopoulos ${ }^{4}$ \\ ${ }^{1}$ IAASARS, National Observatory of Athens, Athens, Greece \\ ${ }^{2}$ Satellite Applications, Met Office, Exeter, UK \\ ${ }^{3}$ Schools of Earth and Atmospheric Sciences and Chemical and Biomolecular Engineering, \\ Georgia Institute of Technology, Atlanta, Georgia, USA \\ ${ }^{4}$ IERSD, National Observatory of Athens, Athens, Greece \\ ${ }^{5}$ ICE-HT, Foundation for Research and Technology Hellas, Patras, Greece \\ ${ }^{6}$ Laboratory of Atmospheric Physics, Aristotle University of Thessaloniki, Thessaloniki, Greece \\ ${ }^{7}$ School of Earth and Environment, University of Leeds, Leeds, UK \\ ${ }^{8}$ Facility for Airborne Atmospheric Measurements (FAAM), Cranfield, UK \\ ${ }^{9}$ School of Earth, Atmospheric and Environmental Sciences, University of Manchester, Manchester, UK \\ ${ }^{10}$ National Centre for Atmospheric Science, University of Manchester, Manchester, UK
}

Correspondence to: Alexandra Tsekeri (atsekeri@noa.gr)

Received: 3 June 2016 - Published in Atmos. Meas. Tech. Discuss.: 18 July 2016

Revised: 12 October 2016 - Accepted: 15 October 2016 - Published: 6 January 2017

\begin{abstract}
We present the In situ/Remote sensing aerosol Retrieval Algorithm (IRRA) that combines airborne in situ and lidar remote sensing data to retrieve vertical profiles of ambient aerosol optical, microphysical and hygroscopic properties, employing the ISORROPIA II model for acquiring the particle hygroscopic growth. Here we apply the algorithm on data collected from the Facility for Airborne Atmospheric Measurements (FAAM) BAe-146 research aircraft during the ACEMED campaign in the Eastern Mediterranean. Vertical profiles of aerosol microphysical properties have been derived successfully for an aged smoke plume near the city of Thessaloniki with aerosol optical depth of $\sim 0.4$ at $532 \mathrm{~nm}$, single scattering albedos of $\sim 0.9-0.95$ at $550 \mathrm{~nm}$ and typical lidar ratios for smoke of $\sim 60-80 \mathrm{sr}$ at $532 \mathrm{~nm}$. IRRA retrieves highly hydrated particles above land, with 55 and $80 \%$ water volume content for ambient relative humidity of 80 and $90 \%$, respectively. The proposed methodology is highly advantageous for aerosol characterization in humid conditions and can find valuable applications in aerosolcloud interaction schemes. Moreover, it can be used for the
\end{abstract}

validation of active space-borne sensors, as is demonstrated here for the case of CALIPSO.

\section{Introduction}

Liquid water is by far the most abundant species in atmospheric particulates, being on average $2-3$ times the total aerosol dry mass on a global average (e.g., Pilinis et al., 1995; Liao and Seinfeld, 2005). Both organic and inorganic compounds contained within aerosol can drive the formation of a liquid aerosol phase (e.g., Guo et al., 2016). Aerosol water uptake changes the particle size and refractive index with profound implications for radiative transfer and cloud formation (e.g., Quinn et al., 2005). For example, at a relative humidity (RH) of $90 \%$, the scattering cross section can increase by a factor of 5 compared to that of the dry particle (Malm and Day, 2001). Because of this, liquid water uptake is the most important contributor to direct radiative cooling by aerosols (Pilinis et al., 1995; Hegg et al., 1997), currently estimated to range between -0.95 and $+0.05 \mathrm{~W} \mathrm{~m}^{-2}$ (IPCC, 
2013). Aerosol liquid water plays also a pivotal role in secondary aerosol formation for inorganic and organic species by promoting the surface area for gas-particle partitioning and by providing the medium for chemical reactions (Seinfeld and Pandis, 2006; Ervens et al., 2011) that assist the formation of aerosol mass.

Acquiring the hydrated particle properties is far from trivial, especially when it comes to vertical profiling. In situ techniques can provide vertically resolved information when applied by an airborne platform, a solution that yields detailed information for particle properties despite being costly and sparse over space and time. Unfortunately, the commonly used in situ techniques can cause alterations in the particle ambient state even when minimally invasive instruments are used (e.g., open-path optical sensors; Snider and Petters, 2008). To address these biases, ambient particle samples are first dried and then rehydrated in the controlled environment of an in situ sensor; aerosol properties and changes thereof are then used to understand the behavior of ambient aerosol for any meteorological state (Engelhart et al., 2011; Pikridas et al., 2012). In contrast to in situ techniques, remote sensing is not invasive and may sample large atmospheric volumes, enabling an unprecedented spatial and temporal coverage for global aerosol monitoring. Passive remote sensing techniques provide columnar particle properties, while active sensors can provide vertically resolved properties. A well-known active remote sensing instrument is the lidar (light detection and ranging), a sensor that is capable of acquiring vertical profiles of the backscatter and extinction coefficients at one or more wavelengths. The illposed nature of the aerosol property retrieval remains the inherent disadvantage of the lidar technique, although considerable algorithmic developments have been achieved over the last decade. These include the employment of sophisticated multi-wavelength elastic/Raman lidar measurements in lidar stand-alone retrievals (e.g., Müller et al., 2016) or the combination of elastic lidar with sun-photometer measurements (e.g., Chaikovsky et al., 2016; Lopatin et al., 2013). Although these advancements have provided means towards more accurate aerosol profiling, still the lidar stand-alone retrievals work well only for fine particles while the lidar/sunphotometer retrievals do not fully resolve the particle microphysical property profiles; they instead provide only the particle concentration profile and consider a constant size distribution and refractive index for the whole atmospheric column.

An alternative hybrid approach for obtaining wellconstrained ambient aerosol profiles is through the synergy of active remote sensing observations with concurrent airborne in situ measurements. To date, such efforts focused mostly on low-humidity profiles, where there is no difference between the ambient remote sensing measurements and the in situ measurements performed under dry conditions inside the instruments (e.g., Weinzierl et al., 2009). High-humidity conditions have also been studied, but only for fine mode particle properties (e.g., Ziemba et al., 2013), as the coarse particle hygroscopic growth is not as easily constrained with in situ airborne techniques, mainly due to sampling inlet loses. The In situ/Remote sensing aerosol Retrieval Algorithm (IRRA) approach presented here addresses these limitations through the combination of in situ and active remote sensing measurements with hygroscopic modeling, making possible the vertical profiling of fine and coarse particles even for humid conditions. For this purpose, the retrieval combines typical airborne in situ instrumentation, measuring the dry particle size distribution and chemical composition, together with a simple backscatter lidar. The ambient remote sensing measurements are linked to the dry in situ data through modeling of the particle hygroscopic growth with the ISORROPIA II model (e.g., Fountoukis and Nenes, 2007; Guo et al., 2015).

In the current study IRRA is applied on data collected in the framework of the EUFAR-ACEMED campaign ("evaluation of CALIPSO's Aerosol Classification scheme over Eastern MEDiterranean"), during which the Facility for Airborne Atmospheric Measurements (FAAM) BAe-146 research aircraft performed two under-flights of the Cloud-Aerosol Lidar and Infrared Pathfinder Satellite Observation (CALIPSO) satellite. The Mediterranean is considered ideal for the application and evaluation of IRRA retrieval scheme, as almost all globally relevant aerosol types are encountered in the region, i.e., dust storms from desert or semiarid areas in Africa, fresh and aged smoke from biomass burning, maritime aerosols, biogenic emissions and anthropogenic aerosols (e.g., Lelieveld et al., 2002).

IRRA methodology is presented in Sect. 2, along with a detailed description of the airborne in situ and lidar measurements acquired during the ACEMED campaign, as well as ISORROPIA II and other models used. Section 3 presents the IRRA results for the ACEMED flight over Thessaloniki, Greece, along with a comparison with the CALIPSO overpass products. In Sect. 4 we discuss our findings, and finally in Sect. 5 we provide our conclusions and the future prospects of this study.

\section{Data and methods}

IRRA methodology is based on the airborne remote sensing and in situ synergy, combining the backscatter lidar measurements with the size distribution, chemical composition, scattering and absorption in situ measurements. Specifically for the ACEMED campaign, airborne active remote sensing observations were performed with the Leosphere ALS450 lidar system acquiring backscatter and depolarization profiles at $355 \mathrm{~nm}$ (Marenco et al., 2011; Chazette et al., 2012); the in situ instruments (Table 1) included the TSI Integrating Nephelometer 3563 for measuring the particle scattering coefficient at 450, 550 and $700 \mathrm{~nm}$, the Radiance Research particle soot absorption photometer (PSAP) for the absorption 
Table 1. The in situ instruments and data acquired from the FAAM BAe-146 research aircraft during the ACEMED campaign.

\begin{tabular}{|c|c|c|}
\hline Property measured & Instrument & Important information about the data \\
\hline \multirow[t]{2}{*}{ Dry aerosol number size distribution } & $\begin{array}{l}\text { Passive cavity aerosol spectrometer probe } \\
100-\mathrm{X} \text { (PCASP) }\end{array}$ & $\begin{array}{l}\text { Nominal size range: } \\
0.05-1.5 \mu \mathrm{m} \text { (radius) }\end{array}$ \\
\hline & $\begin{array}{l}\text { 1.129 GRIMM sky optical particle counter } \\
\text { (GRIMM) }\end{array}$ & $\begin{array}{l}\text { Nominal size range: } 0.125-16 \mu \mathrm{m} \\
\text { (radius) }\end{array}$ \\
\hline $\begin{array}{l}\text { Dry aerosol chemical composition and } \\
\text { mass }\end{array}$ & $\begin{array}{l}\text { Aerodyne time-of-flight aerosol } \\
\text { mass spectrometer (AMS) }\end{array}$ & $\begin{array}{l}\text { Nominal size range: } 0.025-0.4 \mu \mathrm{m} \\
\text { (radius) }\end{array}$ \\
\hline $\begin{array}{l}\text { Dry aerosol light scattering coefficient } \\
\text { at } 450,550 \text { and } 700 \mathrm{~nm}\end{array}$ & $\begin{array}{l}\text { TSI integrating nephelometer } 3563 \text { (neph- } \\
\text { elometer) }\end{array}$ & $\begin{array}{l}\text { We consider a sampling cutoff at } \\
1.5 \mu \mathrm{m} \text { (radius) }\end{array}$ \\
\hline $\begin{array}{l}\text { Dry aerosol light absorption coefficient } \\
\text { at } 567 \mathrm{~nm}\end{array}$ & $\begin{array}{l}\text { Radiance Research particle soot absorption } \\
\text { photometer (PSAP) }\end{array}$ & $\begin{array}{l}\text { We consider a sampling cutoff at } \\
1.5 \mu \mathrm{m} \text { (radius) }\end{array}$ \\
\hline $\mathrm{HCN}$ & $\begin{array}{l}\text { Chemical ionization mass spectrometer } \\
\text { (CIMS) }\end{array}$ & - \\
\hline $\mathrm{CO}$ & Fast fluorescence $\mathrm{CO}$ analyzer & - \\
\hline Water vapor volume mixing ratio & $\begin{array}{l}\text { Water Vapor Sensing System } \\
\text { version two (WVSS-II) }\end{array}$ & - \\
\hline Air temperature & $\begin{array}{l}\text { Rosemount deiced temperature } \\
\text { sensor }\end{array}$ & - \\
\hline Static air pressure & Reduced Vertical Separation Minimum system & - \\
\hline
\end{tabular}

coefficient at $567 \mathrm{~nm}$, the passive cavity aerosol spectrometer probe 100-X (PCASP) and the 1.129 GRIMM sky optical particle counter (GRIMM) for measuring the particle number size distribution, and the Aerodyne time-of-flight aerosol mass spectrometer (AMS) for providing the aerosol chemical composition. Moreover, measurements of trace gases were acquired with the chemical ionization mass spectrometer (CIMS) and the fast fluorescence $\mathrm{CO}$ analyzer, water vapor measurements were provided by the second generation Water Vapor Sensing System (WVSS-II), along with temperature and pressure of the ambient air from the Rosemount deiced temperature sensor and the Reduced Vertical Separation Minimum system, respectively. More details about the instruments and measurements are given in Sect. 2.2 with flight details given in Sect. 3.1.

\subsection{IRRA methodology for retrieving the ambient particle microphysics}

IRRA characterizes the ambient aerosol profiles by utilizing both in situ and remote sensing data through an automated iterative scheme shown schematically in Fig. 1. Briefly, the in situ measured dry particle parameters are "rehydrated" using the ISORROPIA II model to obtain an estimate of the ambient particle size distribution and refractive index. Then, the dry particle scattering and absorption coefficients, together with the ambient particle extinction and backscatter coefficients, are calculated with the Mie theory (Mie, 1908; Bohren and Huffman, 1983). The retrieval is considered successful only if the calculations reproduce the airborne in situ and lidar measurements; if this is not the case the input parameters are adjusted and the process is repeated.

More specifically, for each straight level run (SLR) at a fixed altitude, the in situ dry particle size distribution and refractive index acquired from the PCASP, GRIMM and AMS measurements are used in the retrieval as a first guess for the dry particle characteristics. Then, the dry particle scattering and absorption coefficients are reproduced using the Mie code of Bohren and Huffman (1983), assuming spherical particles in the atmosphere. The in situ optical instrumentation (i.e., TSI integrating nephelometer and PSAP) is affected from inlet and pipeline loses, resulting in coarse particle undersampling, as described in Sect. 2.3.3. For this reason, at this stage we consider a bimodal lognormal size distribution (Eq. 1, red line in Fig. 2) that is truncated up to $1.5 \mu \mathrm{m}$ in radius (black dash line in Fig. 2).

$$
\begin{aligned}
\frac{\mathrm{d} N}{\mathrm{~d} \ln (r)_{\mathrm{d}}} & =\frac{N_{\mathrm{d}_{\mathrm{f}}}}{\sqrt{2 \pi} \ln \left(\sigma_{\mathrm{d}_{\mathrm{f}}}\right)} \exp \left(-\frac{\left(\ln (r)-\ln \left(r_{\mathrm{md}_{\mathrm{f}}}\right)\right)^{2}}{2 \ln \left(\sigma_{\mathrm{d}_{\mathrm{f}}}\right)^{2}}\right) \\
& +\frac{N_{\mathrm{d}_{\mathrm{c}}}}{\sqrt{2 \pi} \ln \left(\sigma_{\mathrm{d}_{\mathrm{c}}}\right)} \exp \left(-\frac{\left(\ln (r)-\ln \left(r_{\mathrm{md}_{\mathrm{c}}}\right)\right)^{2}}{2 \ln \left(\sigma_{\mathrm{d}_{\mathrm{c}}}\right)^{2}}\right)
\end{aligned}
$$

$\frac{\mathrm{d} N}{\mathrm{~d} \ln (r)} \mathrm{d}$ is the dry particle number size distribution, $N_{\mathrm{d}_{\mathrm{f}}}, N_{\mathrm{d}_{\mathrm{c}}}$ are the total number concentrations, $r_{\mathrm{md}_{\mathrm{f}}}, r_{\mathrm{md}_{\mathrm{c}}}$ are the ge- 


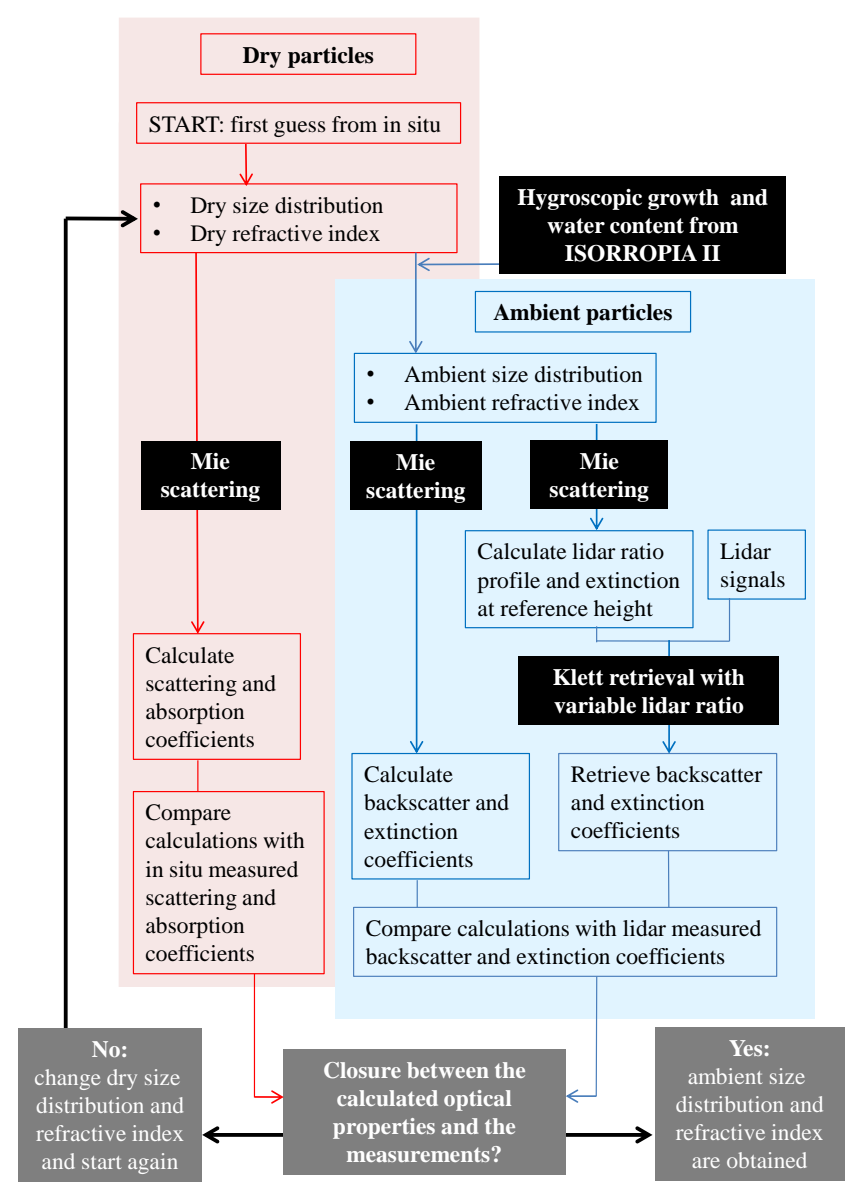

Figure 1. IRRA iterative retrieval scheme used for the estimation of the ambient particle microphysical property profiles, based on the airborne in situ and remote sensing measurements available during the ACEMED campaign and the hygroscopic growth modeling of ISORROPIA II.

ometric mean radii and $\sigma_{\mathrm{d}_{\mathrm{f}}}, \sigma_{\mathrm{d}_{\mathrm{c}}}$ are the geometric standard deviation of fine and coarse modes, respectively.

Moreover, the dry particle refractive index is assumed to be spectrally constant and common for fine and coarse particles. This is necessary since the information content in IRRA is not sufficient to resolve the refractive index spectral and size dependence. As a first guess we use the refractive index calculated from the in situ chemical composition measurements, but this value is only an approximation and is expected to change, since the in situ data do not provide a full chemical characterization of the particles.

The next step, after defining the dry particle size distribution and refractive index, is to estimate the ambient particle properties by modeling their hygroscopic growth with the ISORROPIA II model (a detailed model description is given in Sect. 2.3.1). The ambient particle number size distribution is parameterized similarly to the dry particle number size distribution, considering that the geometric mean radius equals to the dry geometric mean radius multiplied by

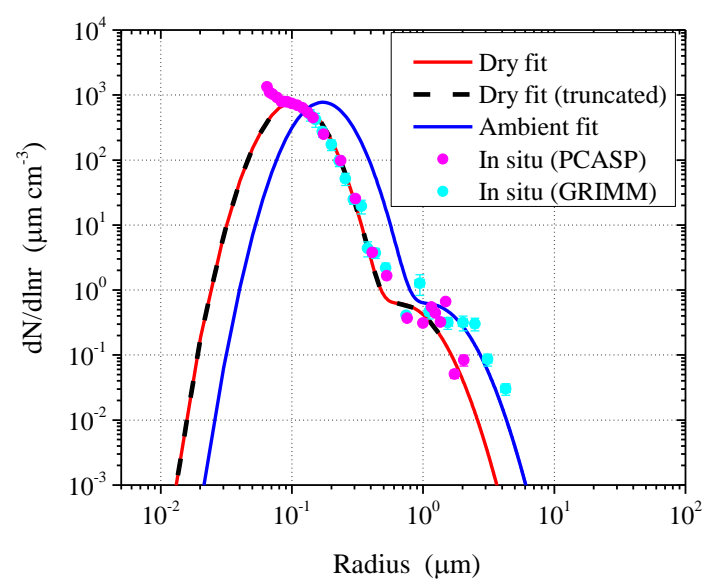

Figure 2. Number size distributions used for the aerosol optical property calculations in IRRA. The red line denotes the bimodal lognormal fit on the measurements, the black dash line the truncated size distribution used to model the dry in situ measured scattering and absorption coefficients and the blue line the hydrated size distribution used to model the ambient backscatter and extinction coefficient lidar measurements. The measured in situ number size distributions are denoted with pink and light blue dots for PCASP and GRIMM OPC data, respectively. The data are acquired at $2.7 \mathrm{~km}$ above Thessaloniki, on 9 September 2011 at 01:04-01:12 UTC, during the ACEMED campaign.

the hygroscopic growth factor $f_{\mathrm{g}}$ of the corresponding mode (Eqs. 2, 3):

$$
\begin{aligned}
& r_{\mathrm{ma}_{\mathrm{f}}}=f_{\mathrm{g}_{\mathrm{f}}} r_{\mathrm{md}_{\mathrm{f}}}, \\
& r_{\mathrm{ma}_{\mathrm{c}}}=f_{\mathrm{g}_{\mathrm{c}}} r_{\mathrm{md}_{\mathrm{c}}} .
\end{aligned}
$$

The subscripts $f$ and $c$ denote the fine and coarse particle modes, respectively. The corresponding $f_{\mathrm{g}}$ values are calculated from the water uptake predicted with ISORROPIA II. $r_{\mathrm{maf}_{\mathrm{f}}}$ and $r_{\mathrm{mac}_{\mathrm{c}}}$ are the geometric mean radii of the modes. An example of an ambient size distribution retrieval is shown in Fig. 2 (blue line) for $\mathrm{RH}=81 \%$.

The real and imaginary parts of the ambient particle refractive index are calculated as follows:

$n_{\mathrm{af}, \mathrm{c}}(\lambda)=\left(1-f_{\mathrm{w}_{\mathrm{f}, \mathrm{c}}}\right) n_{\mathrm{d}_{\mathrm{f}, \mathrm{c}}}+f_{\mathrm{w}_{\mathrm{f}, \mathrm{c}}} n_{w}(\lambda)$,

$k_{\mathrm{a}_{\mathrm{f}, \mathrm{c}}}(\lambda)=\left(1-f_{\mathrm{w}_{\mathrm{f}, \mathrm{c}}}\right) k_{\mathrm{d}_{\mathrm{f}, \mathrm{c}}}+f_{\mathrm{w}_{\mathrm{f}, \mathrm{c}}} k_{w}(\lambda)$,

where $n_{\mathrm{af}, \mathrm{c}}(\lambda)$ and $k_{\mathrm{af}, \mathrm{c}}(\lambda)$ are the real and imaginary parts of the ambient refractive index, $n_{\mathrm{d}_{\mathrm{f}, \mathrm{c}}}$ and $k_{\mathrm{d}_{\mathrm{f}, \mathrm{c}}}$ are the same for dry particles, $n_{w}(\lambda)+\mathrm{ik}_{w}(\lambda)$ is the water refractive index, $\lambda$ is the wavelength and $f_{\mathrm{w}_{\mathrm{f}, \mathrm{c}}}$ are the water volume fractions in total volume of the ambient particles, provided by ISORROPIA II.

At the last stage, the measured optical properties are reproduced with Mie calculations, and closure is achieved between measurements and calculations. These properties are the backscatter and extinction coefficients at $355 \mathrm{~nm}$ calculated from the ambient properties and the scattering coefficients at $450,550,700 \mathrm{~nm}$ and absorption coefficient at 
$567 \mathrm{~nm}$ calculated from the dry properties. The closure is achieved through the minimization of a cost function, using the trust-region reflective optimization algorithm (based on the interior-reflective Newton method described in Coleman and $\mathrm{Li}, 1994,1996)$. The cost function is the sum of the squares of the differences between the measured and calculated optical properties, weighted by their "importance" for the retrieval, as described in more detail in Appendix A. Briefly, starting from a first guess for the parameters of the dry particle size distribution and refractive index, the optimization algorithm iteratively searches the parameter space for a set that minimizes the cost function. The search is set to stop after few $(\sim 10)$ iterations, after which there is no considerable change in the cost function reduction or in the step size for the current study. Ideally, in case of quantified uncertainties in the measurements and the parameters, the search stops when the cost function reduction is smaller than the uncertainty of the measurements or the search step size is smaller than the uncertainty of the parameter space (Dubovik, 2004). At the end, the retrieval errors can be quantified using the measurement uncertainties and the Jacobian matrix of the final optimization step (Rodgers, 2000; Dubovik, 2004).

\subsection{Data}

\subsubsection{Airborne lidar}

The airborne active remote sensing observations used in IRRA for the ACEMED campaign were performed with the nadir-pointing Leosphere ALS450 lidar system, capable of acquiring particle backscatter and depolarization profiles at $355 \mathrm{~nm}$ (Marenco et al., 2011; Chazette et al., 2012). The measurements were acquired at night-flight, and the absence of daylight allowed the airborne lidar to measure with good signal-to-noise ratio (SNR). Lidar signals were measured with an integration time of $2 \mathrm{~s}$ and a vertical resolution of $1.5 \mathrm{~m}$ and are smoothed vertically to a $45 \mathrm{~m}$ vertical resolution in order to improve SNR further. The vertical profiles of lidar signals are then cloud-screened by eliminating those in the presence of clouds using the thresholds in Allen et al. (2014).

The particle backscatter and extinction coefficients from the ALS450 system observations are calculated following the solution by Klett (1985), assuming a variable extinction-tobackscatter ratio or lidar ratio (LR) at $355 \mathrm{~nm}$ with height, and an aerosol extinction coefficient at $355 \mathrm{~nm}$ at a reference height in the far range. Both LR and reference extinction are calculated from the retrieved ambient size distribution and refractive index at the corresponding heights (see Fig. 1).

\subsubsection{Airborne in situ}

\section{Particle drying from in situ instruments}

The sampled air is dried by adiabatic compression during the sampling through the inlets of the aircraft in situ instruments and by the cabin temperature and radiant heat from the lights inside the instruments. There is a chance this drying is only partial, with some residual water remaining in the sample (e.g., Strapp et al., 1992; Snider and Petters, 2008). The partial drying is estimated from the instrument $\mathrm{RH}$ (and the particle chemical composition) and is taken into account in modeling the particle hygroscopic growth with ISORROPIA II. Unfortunately, instrument RH measurements are provided only for the nephelometer, with values ranging at $\sim 25-40 \%$. We assume that these values are the same for PSAP. For PCASP and GRIMM optical particle counter (OPC) measurements we consider a low RH of $30 \%$, based on the work of Strapp et al. (1992). Strapp et al. (1992) indicated that particles with radius less than $5 \mu \mathrm{m}$ should be dehydrated due to the residence time of $0.1-0.3 \mathrm{~s}$ in the low-humidity environment of the instrument. Even if this is not the case, the RH of $30 \%$ has a minor effect on particle hydration for the samples analyzed here, causing $\sim 1 \%$ growth in particle size. For the sake of simplicity herein we call the partially dried particles as "dry particles".

\section{Particle size distribution measurements}

The number size distributions were measured with PCASP and GRIMM OPCs. Both instruments measure the particle number size distribution by impinging light on the air sample and inferring the number and size of the particles from the light each particle scatters over a specified angular range (Rosenberg et al., 2012; Heim et al., 2008). PCASP operates a helium-neon laser at $0.6328 \mu \mathrm{m}$, measuring the particle scattering at $35-120^{\circ}$ (primary angles) and $60-145^{\circ}$ (secondary angles), providing a (nominal) size range of $0.05-$ $1.5 \mu \mathrm{m}$ radius. GRIMM uses the light of a laser diode at $0.683 \mu \mathrm{m}$, measuring at $30-150^{\circ}$ (primary angles) and $81-$ $99^{\circ}$ (secondary angles), providing a (nominal) size range of $0.125-16 \mu \mathrm{m}$ radius. The number of particles equals to the scattered light pulses, since each particle in the sample results in a light pulse. The particle size is calculated comparing the height and width of the pulse with that from calibration standards of known size distribution and refractive index, assuming that the sample has the same refractive index as the calibration standard. This is the "nominal size" and the true size can be then derived correcting for the particle refractive index, as described in Rosenberg et al. (2012). For the PCASP we use the calibration standards from the Fennec 2011 campaign (Rosenberg et al., 2012), and for the GRIMM we generate calibration standards assuming a bin width uncertainty of $5 \%$, based upon the manufacturers' specification. A de- 
tailed description of handling and correcting the OPC size distribution data is provided in Appendix B.

The PCASP was wing-mounted on the BAe-146 aircraft, whereas the GRIMM was internally mounted and connected with a Rosemount inlet, sampling the air through different inlets and pipelines. The effects of inlet efficiencies (enhancement/losses) and loses along the pipelines varied with altitude and ambient size distribution, affecting mainly the coarse mode particles (Ryder et al., 2013; Trembath et al., 2012). Inlet efficiency corrections are applied to PCASP using the methods of Belyaev and Levin (1974). The GRIMM OPC was not corrected for particle losses, and we expect the main loses to be for the largest particles.

As a validation of correctly handling the PCASP and GRIMM data, we compare the derived PCASP and GRIMM number size distributions (after converting them to volume size distributions) with the ambient volume size distributions provided by AERONET measurements on the days before and after the BAe-146 aircraft night flight (Fig. 3). Note that the AERONET does not provide vertically resolved products, but rather the effective-column volume size distribution with units $\mu \mathrm{m}^{3} \mu \mathrm{m}^{-2}$. For a direct comparison with PCASP and GRIMM data (in $\mu \mathrm{m}^{3} \mathrm{~cm}^{-3}$ ) we divide the AERONET size distribution with the aerosol layer height (derived by the lidar measurements to be equal to $\sim 3.5 \mathrm{~km}$ ). The OPC data uncertainties in the plot of Fig. 3 are calculated considering the refractive index uncertainty (Rosenberg et al., 2012) and counting statistics (see Appendix B). For fine mode there is a very good agreement among the two OPCs, but this is not the case for particles with radius $>1.5 \mu \mathrm{m}$. The AERONET volume size distributions are similar to in situ measurements for the fine mode, with the AERONET observations before the flight to be within $\sim \pm 60 \%$ of the PCASP and GRIMM particle volume for particles with radius $<1.5 \mu \mathrm{m}$. Similar results are shown in Haywood et al. (2003) for $0.1-1.0 \mu \mathrm{m}$ radius range, for their fresh smoke aerosol plumes. For particles with radius $>1.5 \mu \mathrm{m}$ the agreement is worse, especially for GRIMM data, owing to the Rosemount inlet enhancement of the super-micron particles (as described in Trembath et al., 2012). This is to be expected, since for sizes $>1.5 \mu \mathrm{m}$ the agreement between PCASP and GRIMM deteriorates as well. In any case, the comparison with AERONET data should be done with caution, since it refers to ambient particles, and the measurements are offset by $\sim 9 \mathrm{~h}$. The differences can be also attributed to the AERONET size distribution cutoff at $15 \mu \mathrm{m}$. In general though, the good agreement for particles with radius $<1.5 \mu \mathrm{m}$ for all three datasets indicates that the airborne in situ measurements of PCASP and GRIMM instruments provide trustworthy data for this size range, fitted to be used in our analysis.

\section{Chemical composition and refractive index}

The aerosol composition and mass distribution of volatile and semivolatile components of aerosols as a function of par-

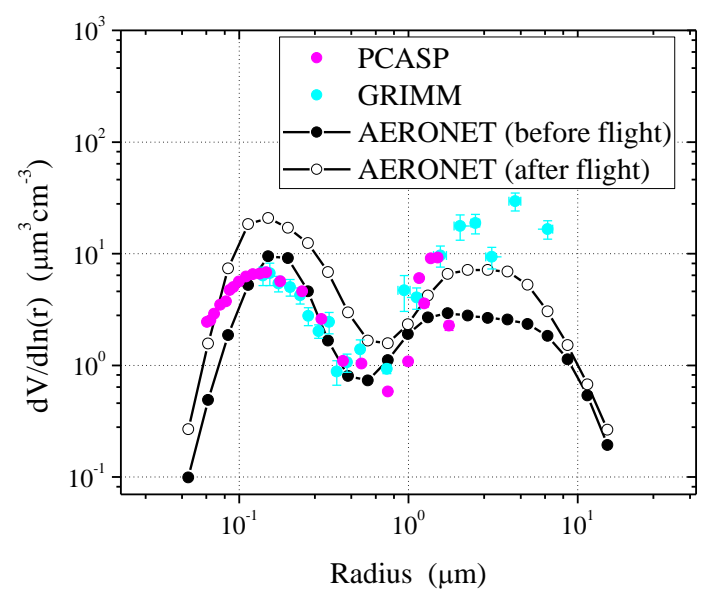

Figure 3. The measured dry volume size distributions from PCASP (pink) and GRIMM (light blue), acquired at $2.7 \mathrm{~km}$ above Thessaloniki on 9 September 2011 at 01:04-01:12 UTC. The vertical error bars denote the volume uncertainty estimates, and the horizontal error bars the bin width uncertainties. The black lines indicate the column ambient size distributions from AERONET before (at 8 September 2011, 15:28 UTC, denoted with filled circles) and after the flight (at 9 September 2011, 08:25 UTC, denoted with open circles).

ticle size (with radius from 0.025 to $0.4 \mu \mathrm{m}$ ) were measured with the AMS instrument (Allan et al., 2003; Morgan et al., 2010; Athanasopoulou et al., 2015). AMS measures the mass loadings of the refractive aerosol fractions: sulfates, nitrates, ammonium, chloride and organics. Figure 4 shows the AMS measurements for the ACEMED case analyzed here, indicating mixtures of inorganics/organics in the range of $\sim 50 / 50$ (the chloride mass concentration is very low and is not shown in the plot). Although the data refer mainly to fine mode particles, in our analysis we assume that they are representative of the coarse mode as well, since there are no measurements for the coarse particle chemical composition (the "coarse mode" denotes here to particles with radius $>0.8 \mu \mathrm{m}$ - see Fig. 3).

The chemical composition provided by the AMS can be used to estimate the particle refractive index, assuming that the particles are internally mixed and applying a volume mixing law to account for the contributions of the corresponding chemical groups (Highwood et al., 2012). For the calculations we need to consider a characteristic refractive index for each chemical group as well as a density to convert the AMS-measured dry mass to volume. Here we use the values provided in Highwood et al. (2012) (see Table 2): we assume the sulfate, nitrate and ammonium particles to be in the form of ammonium sulfate $\left(\left(\mathrm{NH}_{4}\right)_{2} \mathrm{SO}_{4}\right)$ and ammonium nitrate $\left(\mathrm{NH}_{4} \mathrm{NO}_{3}\right)$, with density and refractive index provided by Toon (1976) and Weast (1985), respectively. For organics, we consider the properties of the organic carbon of the Suwannee River fulvic acid, as reported in Dinar et al. (2006, 2008). 


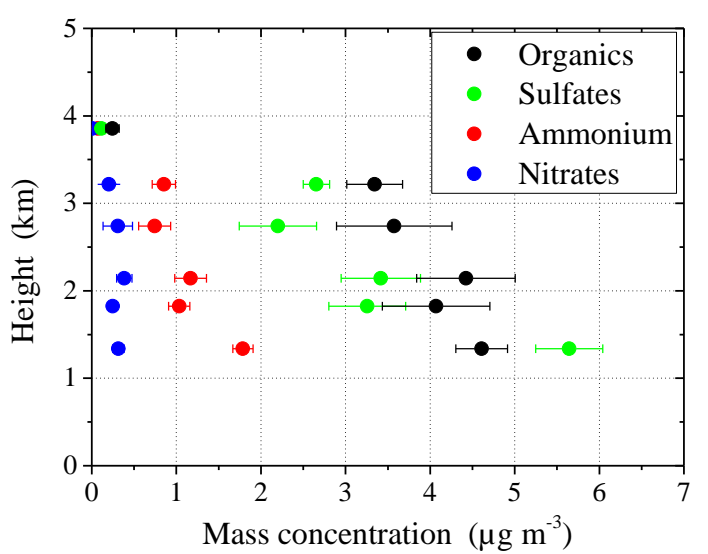

Figure 4. The measured dry mass concentrations from AMS for organics, sulfates, ammonium and nitrates, acquired during the ACEMED campaign above Thessaloniki, on 9 September 2011 at 00:05-01:45 UTC. The error bars denote the horizontal variability on each SLR.

Table 2. Refractive indices and densities used for the refractive index calculation from AMS data acquired from the FAAM BAe-146 research aircraft during the ACEMED campaign.

\begin{tabular}{llll}
\hline Chemical species & $\begin{array}{l}\text { Refractive index } \\
\text { at } 550 \mathrm{~nm}\end{array}$ & $\begin{array}{l}\text { Density } \\
\left(\mathrm{g} \mathrm{cm}^{-3}\right)\end{array}$ & References \\
\hline $\begin{array}{l}\text { Ammonium sulfate } \\
\left(\mathrm{NH}_{4}\right)_{2} \mathrm{SO}_{4}\end{array}$ & $1.53-0 i$ & 1.77 & Toon (1976) \\
\hline $\begin{array}{l}\text { Ammonium nitrate } \\
\mathrm{NH}_{4} \mathrm{NO}_{3}\end{array}$ & $1.611-0 i$ & 1.8 & Weast (1985) \\
\hline $\begin{array}{l}\text { Organic carbon of } \\
\text { the Suwannee } \\
\text { River fulvic acid }\end{array}$ & $1.538-0.02 i$ & 1.5 & $\begin{array}{l}\text { Dinar et } \\
\text { al. }(2006,2008)\end{array}$ \\
\hline
\end{tabular}

This approach is quite approximate, especially considering the refractive index variability of the "organics" group. In addition, the aerosol sampled is influenced by biomass burning (mainly due to high $\mathrm{HCN}$ and $\mathrm{CO}$ concentrations measured - see Sect. 3.1) and may be strongly absorbing - this means that the uncertainty on the imaginary part is large. For these reasons the AMS-derived refractive index is used only as a first guess for the refractive index calculation with IRRA algorithm, as described in the methodology Sect. 2.1. A similar approach was followed from McConnell et al. (2010), although focusing mainly on the imaginary part retrieval.

\section{Scattering and absorption}

The dry particle scattering coefficients at 450, 550 and $700 \mathrm{~nm}$ were measured on board with the TSI Integrating Nephelometer 3563 and the absorption coefficient at $567 \mathrm{~nm}$ was measured with the PSAP (Orgen, 2010). The scattering coefficient measurements are corrected for angular truncation, temperature and pressure (Anderson and Orgen, 1998; Turnbull, 2010). The absorption measurements are corrected for pressure, flow rate and spot size effects (Bond et al., 1999; Orgen, 2010; Turnbull, 2010). Both instruments were connected to modified Rosemount inlets (Trembath et al., 2012), suffering from inlet enhancement/losses as well as losses along the pipelines, and consequently did not measure the scattering properties of the whole particle size range. For this reason, we consider a sampling cutoff for particles with radius $>1.5 \mu \mathrm{m}$ for the TSI Integrating Nephelometer and PSAP measurements.

\section{Ambient relative humidity}

The ambient RH is estimated from the water vapor measurements from the WVSS-II instrument (Fleming and May, 2004). The WVSS-II uses a near-infrared tunable diode laser absorption spectrometer. Two WVSS-II instruments were mounted on the BAe-146 aircraft, sampling the air through the standard flush inlet and a modified Rosemount inlet, respectively. The water vapor measurements provided by the two instruments can be different (Vance et al., 2015), but for the case presented here the differences are small, of the order of less than $2 \%$ in ambient $\mathrm{RH}$; thus what we used in our analysis is their average. The ambient RH calculation from the WVSS-II water vapor measurements is provided in Appendix C.

\subsection{Models}

\subsubsection{Hygroscopic growth model}

ISORROPIA II (Nenes et al., 1998a, b; Fountoukis and Nenes, 2007) models the phase state and composition of aerosol composed of $\mathrm{Na}, \mathrm{NH}_{4}, \mathrm{NO}_{3}, \mathrm{Cl}, \mathrm{SO}_{4}, \mathrm{Mg}, \mathrm{K}, \mathrm{Ca}$ and $\mathrm{H}_{2} \mathrm{O}$ in equilibrium with a gas phase composed of $\mathrm{NH}_{3}$, $\mathrm{HNO}_{3}$ and $\mathrm{HCl}$. The model performance has been evaluated against comprehensive ambient datasets over a wide range of acidities, RH and temperatures (Fountoukis and Nenes, 2007; Fountoukis et al., 2009; Hennigan et al., 2015; Guo et al., 2015; Weber et al., 2016; Guo et al., 2016). In our analysis, we also consider the contribution of hygroscopic organics to the water uptake of the aerosol using the approach of Guo et al. (2015).

ISORROPIA II takes as input the aerosol precursor composition, along with the temperature, pressure and $\mathrm{RH}$ of the sample inside the instrument and the temperature, pressure and RH of the ambient atmosphere, and it calculates the hygroscopic growth of fine and coarse modes. Since we assume the same chemical composition for fine and coarse particles, the hygroscopic growth is the same for both. The calculations involve various uncertainties, mainly from the hygroscopicity of the organic matter, the uncertainties and/or the variability in the $\mathrm{RH}$ measurements and the size dependence of composition (that is not considered) within each mode and between modes. 


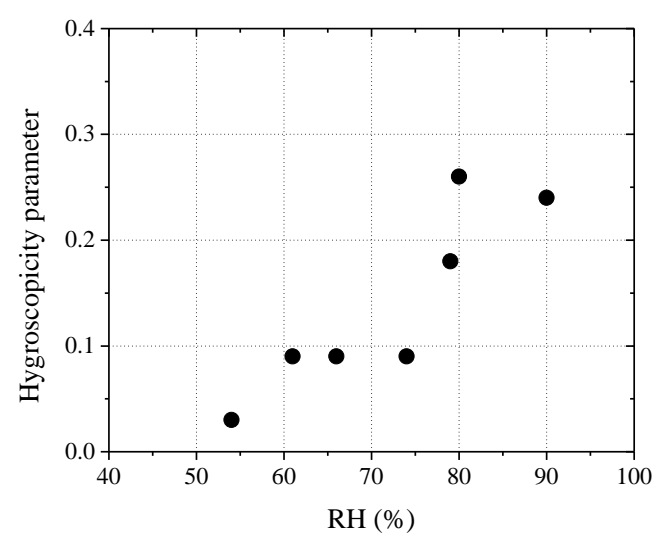

Figure 5. Hygroscopicity parameter calculated with ISORROPIA II for the different RHs of the flight above Thessaloniki, Greece, on 9 September 2011 during the ACEMED campaign.

Overall, ISORROPIA II provides an excellent estimation of the particle hygroscopic growth, especially at high RHs where the hydration has the greatest effect on the particle properties (e.g., Guo et al., 2015). The cumulative effect of particle composition on water uptake can be expressed using the hygroscopicity parameter $\kappa$ (Petters and Kreidenweis, 2007), derived from $f_{\mathrm{g}}$ and $\mathrm{RH}$ as in Eq. (6):

$\kappa=\frac{f_{\mathrm{g}}^{3}-1}{\mathrm{RH} / 100-\mathrm{RH}}$.

For mixtures of inorganics/organics in the range of $\sim 50 / 50$, as is the case here, the hygroscopicity parameter is 0.2 0.3 for RH $>80 \%$ (Petters and Kreidenweis, 2007; Chang et al., 2010; Mikhailov et al., 2013). Airborne measurements performed above the Aegean Sea during the Aegean-Game (Aegean Pollution: Gaseous and Aerosol airborne MEasurements) campaign (Bezantakos et al., 2013), which was coupled with ACEMED, showed similar values for $\kappa$. Over multiple years, measurements of particle hygroscopicity at the South Aegean site of Finokalia, Crete, also exhibit very similar values (Bougiatioti et al., 2009, 2011, 2016; Kalkavouras et al., 2016). ISORROPIA II retrieves $\kappa \approx 0.25$ for $\mathrm{RH}>80 \%$ and lower values for smaller RHs (see Fig. 5). Given that the hygroscopic growth data reported by Bezantakos et al. (2013) correspond to RH $>80 \%$, this consistency between predictions and observations is a strong indication that the internal mixture assumption applies and that the AMS composition data are representative of the ambient aerosol. Moreover, the drop in predicted hygroscopicity for $\mathrm{RH}<80 \%$ is consistent with observed behavior for aerosol particles (e.g., Guo et al., 2015).

\subsubsection{Source-receptor simulations}

In order to investigate the origin of the aerosol plumes in the scene analyzed here, a number of backward and forward Lagrangian simulations of particle dispersion are performed with FLEXPART-WRF model (Brioude et al., 2013). These simulations are driven by WRF_ARW (Skamarock et al., 2008) hourly fields at $4 \times 4 \mathrm{~km}$ horizontal resolution. Initial and boundary conditions for the WRF model are from the National Centers for Environmental Prediction (NCEP) final analysis (FNL) product at $1^{\circ} \times 1^{\circ}$ resolution. The sea surface temperature (SST) is the daily NCEP SST analysis at $0.5^{\circ} \times 0.5^{\circ}$ resolution. Furthermore, in order to derive information of smoke dispersion for the forward runs, fire hot spots are obtained from the Moderate Resolution Imaging Spectroradiometer (MODIS) Fire Information for Resource Management System (FIRMS) database.

\subsection{CALIPSO product}

The derived ambient particle properties during the ACEMED campaign are used to evaluate the CALIPSO products. CALIPSO satellite carries CALIOP, an elastic backscatter lidar operating at 532 and $1064 \mathrm{~nm}$, equipped with a depolarization channel at $532 \mathrm{~nm}$, delivering global vertical profiles of aerosols and clouds. The CALIPSO Level-2 (L2) aerosol layer products used in the current study are generated by automated algorithms and provide a description of the aerosol layers in respect to horizontal and vertical extend, along with the particle backscatter and extinction coefficient profiles. A detailed description of the L2 algorithms is provided in Vaugan et al. (2004) and Winker et al. (2009).

The CALIPSO Vertical Feature Mask (VFM) L2 product (Vaughan et al., 2004) classifies aerosols and clouds based on their optical properties and external information of geographical location, surface type and season (Omar et al., 2005, 2009). The classification scheme differentiates six subtypes of aerosol particles: polluted continental, smoke, dust, polluted dust, clean marine and clean continental. An example of the attenuated backscatter coefficient and the associated VFM classification, for the case analyzed here, is shown in Fig. 7b and c. Burton et al. (2013) have validated the CALIPSO classification scheme using collocated airborne high spectral resolution lidar (HSRL) measurements during 109 CALIPSO under-flights and reported a relatively trustworthy classification for mineral dust $(80 \%)$ which falls to $62 \%$ for marine particles, $54 \%$ for polluted continental, $35 \%$ for polluted dust and only $13 \%$ for smoke.

\section{Results}

\subsection{ACEMED flight overview}

The scope of the ACEMED EUFAR campaign was the evaluation of the CALIPSO aerosol classification scheme us- 
(a)

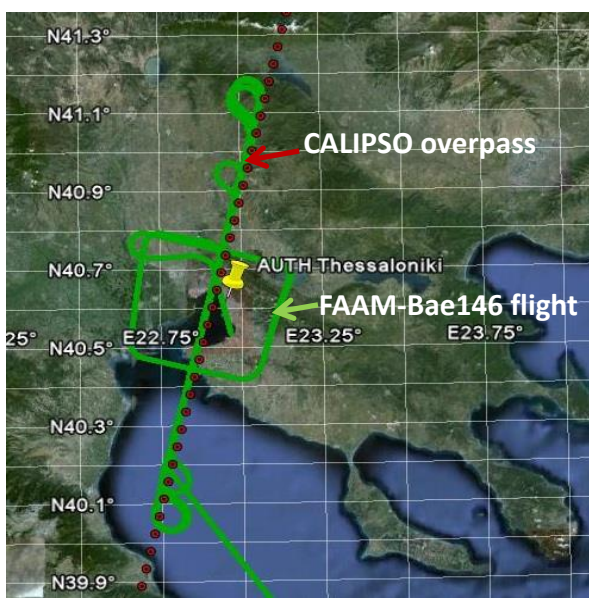

FAAM BAe-146 flight path

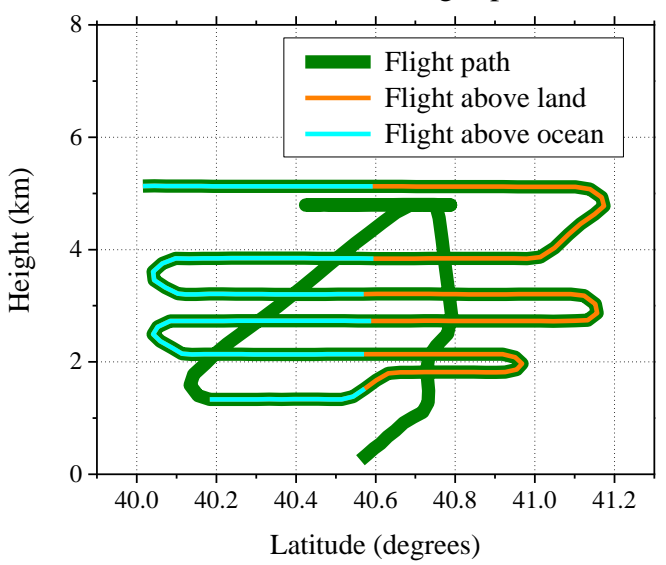

Figure 6. (a) The FAAM BAe-146 aircraft flight track above Thessaloniki, Greece, on 9 September 2011 at 00:05-01:50 UTC (green line) and the CALIPSO track at 00:31 UTC (red dots). (b) The FAAM BAe-146 flight latitude-altitude profile (green line). The flight segments used in the current analysis are denoted with orange color above land and with light blue color above ocean.

ing high quality airborne aerosol measurements along with ground-based lidar, sun photometric and in situ observations. ACEMED was clustered with the Aegean-Game campaign (Tombrou et al., 2015), held from 31 August to 9 September 2011 with the FAAM (http://www.faam.ac.uk/) BAe-146 research aircraft, based in the island of Crete (Greece). Two CALIPSO under-flights were performed for ACEMED, on 2 September and during the night between 8 and 9 September. Here only the latter flight is considered (FAAM flight B644, Fig. 6) due to higher SNR lidar measurements during the night.

The BAe-146 aircraft approached Thessaloniki area from the southeast, flying at an altitude of $\sim 5 \mathrm{~km}$ above mean sea level. Once in the operating area, it flew on a SSW to NNE transect back and forth between 40 and $41.2^{\circ} \mathrm{N}$, sampling at different altitudes over both land and ocean (coastline at $40.6^{\circ} \mathrm{N}$; see Fig. 6). A first SLR was done at $5.1 \mathrm{~km}$ altitude, above the aerosol layers, so as to provide full profiles with the use of the onboard lidar. Then, the aircraft flew a series of SLRs at altitudes 3.9, 3.2, 2.7, 2.1, 1.8 and $1.3 \mathrm{~km}$, and in each of these data have been collected with the in situ instrumentation. The aircraft then profiled the atmosphere, returning to high level $(4.8 \mathrm{~km})$ for an additional remote sensing survey in the shape of a box pattern around the sampling area. The lidar measurements used in the current analysis were acquired when the aircraft was flying at 5.1 and $4.8 \mathrm{~km}$, and the in situ measurements were acquired at 3.2, 2.7, 2.1, 1.8 and $1.3 \mathrm{~km}$ (at 5 and $3.9 \mathrm{~km}$ the in situ data showed no presence of particles).

Figure 7 shows the vertical profiling of the atmosphere along the flight, as depicted in the range-corrected backscatter signal at $355 \mathrm{~nm}$ from the airborne lidar (Fig. 7a), and the curtain of the attenuated backscatter coefficient as this is provided by CALIPSO L1 product at $532 \mathrm{~nm}$ (Fig. 7b). The airborne lidar depolarization measurements were low (not shown here), indicating spherical particles in the scene. In both Fig. 7a and $\mathrm{b}$ there is strong indication of cloud formation at $\sim 3 \mathrm{~km}$ in part of the flight above land (shown as white features). Large RHs have also been observed in the airborne WVSS-II RH measurements in Fig. 8 at that height, where the cloudy parts above land show RHs of $92-98 \%$. These cloudy parts are excluded from the CALIPSO aerosol subtype VFM product (see Fig. 7c) and the corresponding lidar vertical profiles are excluded from our analysis. At the cloudfree parts the RH is higher above land $(80-90 \%$ at $2-3.5 \mathrm{~km}$ and $60 \%$ below $2 \mathrm{~km})$ and lower above ocean $(70-80 \%$ at $2-3 \mathrm{~km}$ and $<60 \%$ below $2 \mathrm{~km}$ ) (Fig. 8).

FLEXPART source-receptor simulations show the advection of smoke from biomass burning towards the region of interest in Fig. 9. The wind direction over the Balkans was mainly NW. However, due to the complex topography at the area and the development of low-level thermal circulations along the coastlines (sea breeze), the wind pattern at the lowest $1 \mathrm{~km}$ in the troposphere was rapidly changing with time, affecting also the dispersion of smoke. Such wind channeling and sea-breeze formation is adequately resolved in the finer WRF grids. The emission sensitivity (residence time) for a $24 \mathrm{~h}$ backwards simulation and for two representative locations (one over land and one over ocean) is shown in Fig. 9a. The red triangles denote the position of the active fires during this period as obtained by the MODIS fire product (https://earthdata.nasa. gov/earth-observation-data/near-real-time/firms). These results identify six hot spots that fall within the emission sensitivity area and so are most likely responsible for the smoke transport over the region of interest.

Taking into account the positions and times of detection of the six emission points we perform a forward simula- 


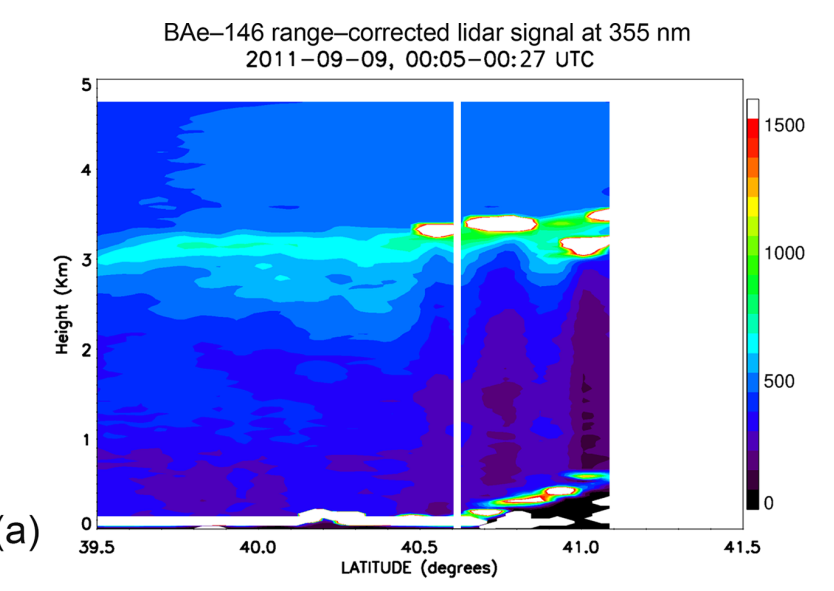

(b)
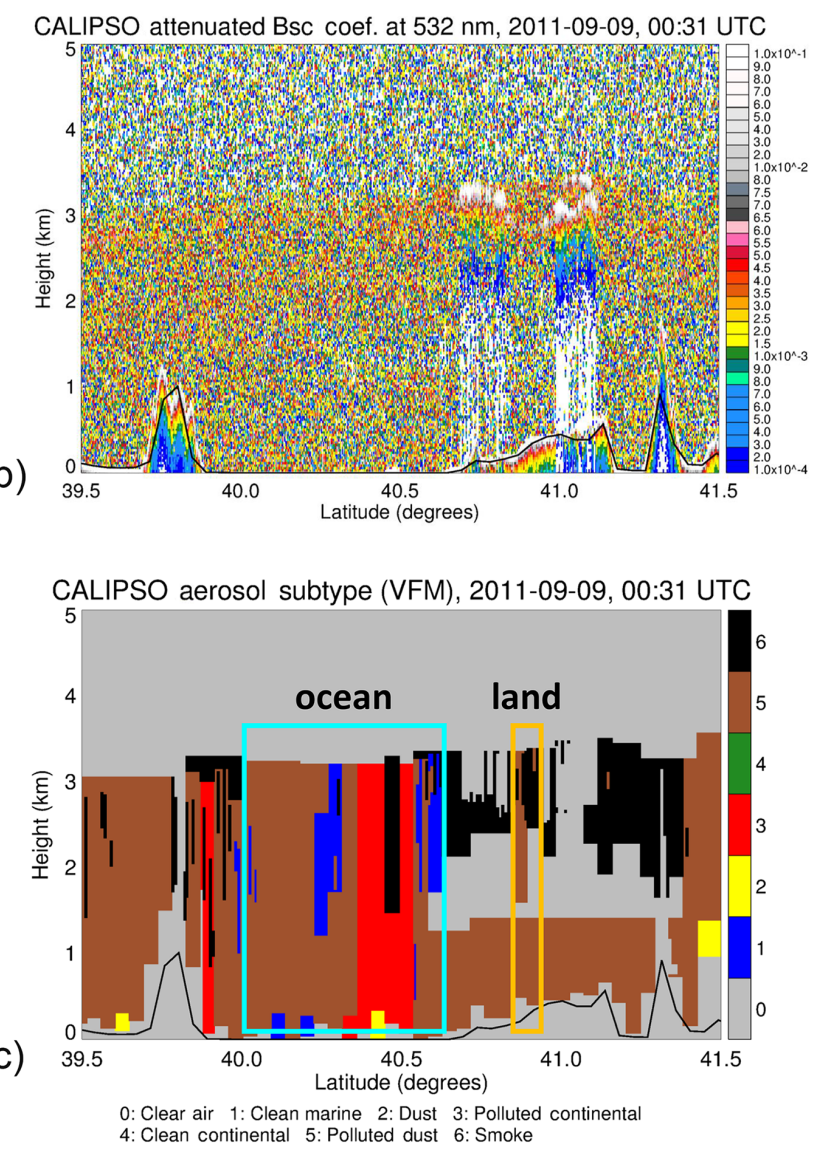

Figure 7. (a) The Leosphere ALS450 lidar range-corrected signal at $355 \mathrm{~nm}$, for the FAAM BAe-146 flight, above Thessaloniki, Greece, on 9 September 2011 at 00:05-00:27 UTC (the white line separates the ocean and land parts, at $40.6^{\circ} \mathrm{N}$ latitude). (b) The CALIPSO attenuated backscatter coefficient at $532 \mathrm{~nm}$; (c) the CALIPSO aerosol subtypes (VFM) for the CALIPSO overpass at 00:31 UTC. The light blue and orange rectangles mark the area used to compare with the FAAM BAe-146 flight measurements above ocean and land, respectively.

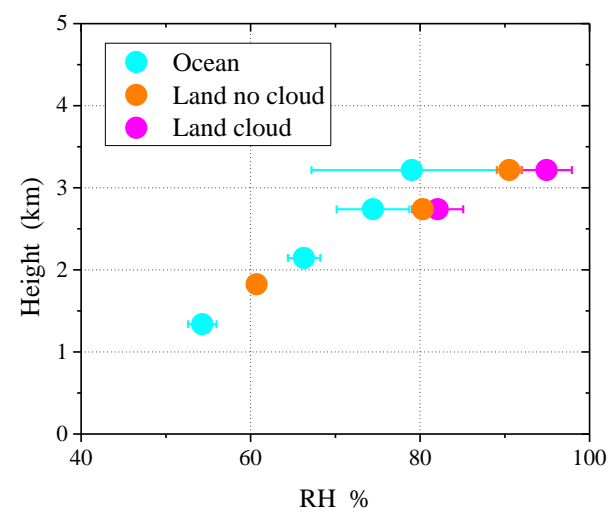

Figure 8. Averaged RH measurements from the WVSS-II instrument, above land (orange circles for cloud-free area and pink circles for cloudy area) and ocean (light blue circles), during the FAAM BAe-146 aircraft flight above Thessaloniki, Greece, on 9 September 2011 at 00:48-01:50 UTC.

tion of smoke dispersion, assuming constant emission rates of $0.15 \mathrm{~kg} \mathrm{~s}^{-1}$ and constant smoke injection heights at $1 \mathrm{~km}$. The vertical cross section of smoke total particulate matter (TPM) is shown in Fig. 9b (the location of the cross section is indicated by the dashed black line in Fig. 9a). In order to compensate for the possible time lags in modeled smoke transport we compute the average TPM concentration for the period 00:00-02:00 UTC from the corresponding 30 min model outputs (i.e., 00:00, 00:30, 01:00, 01:30 and 02:00 UTC). Figure 9b shows elevated smoke plumes over the northern land part at about $2-3 \mathrm{~km}$ and near the surface (the latter though being below the FAAM BAe-146 flight level). The results indicate also the presence of a lower $(1-2.5 \mathrm{~km})$ smoke plume over the ocean. The elevated smoke plumes above the southern land part in Fig. $9 \mathrm{~b}$ are out of the FAAM BAe-146 flight range.

The smoke presence above Thessaloniki is also supported by the biomass burning proxies $\mathrm{HCN}$ and $\mathrm{CO}$ measurements, acquired with CIMS (Le Breton et al., 2013) and the fast fluorescence CO analyzer (Gerbig et al., 1999), respectively. The HCN is used as a biomass burning tracer (Lobert et al., 1990) since its lifetime in the smoke plume can potentially exceed several weeks. As indicated in Le Breton et al. (2013), HCN concentrations higher than 6 standard deviations from the median background concentration are highly correlated with $\mathrm{CO}$ concentrations indicating biomass burning plumes. Indeed, the HCN concentrations seem to exceed the smoke plume detection threshold at altitudes from 2 to $3.5 \mathrm{~km}$ (Fig. 10). These values are strongly correlated with the corresponding $\mathrm{CO}$ concentrations, with a correlation of $R^{2}=0.8$ (not shown here), strongly indicating the smoke presence. The measurements agree well with sourcereceptor simulations in Fig. 9, except for the lower part of the smoke plume above the ocean, which is not depicted in the $\mathrm{HCN}$ data. 

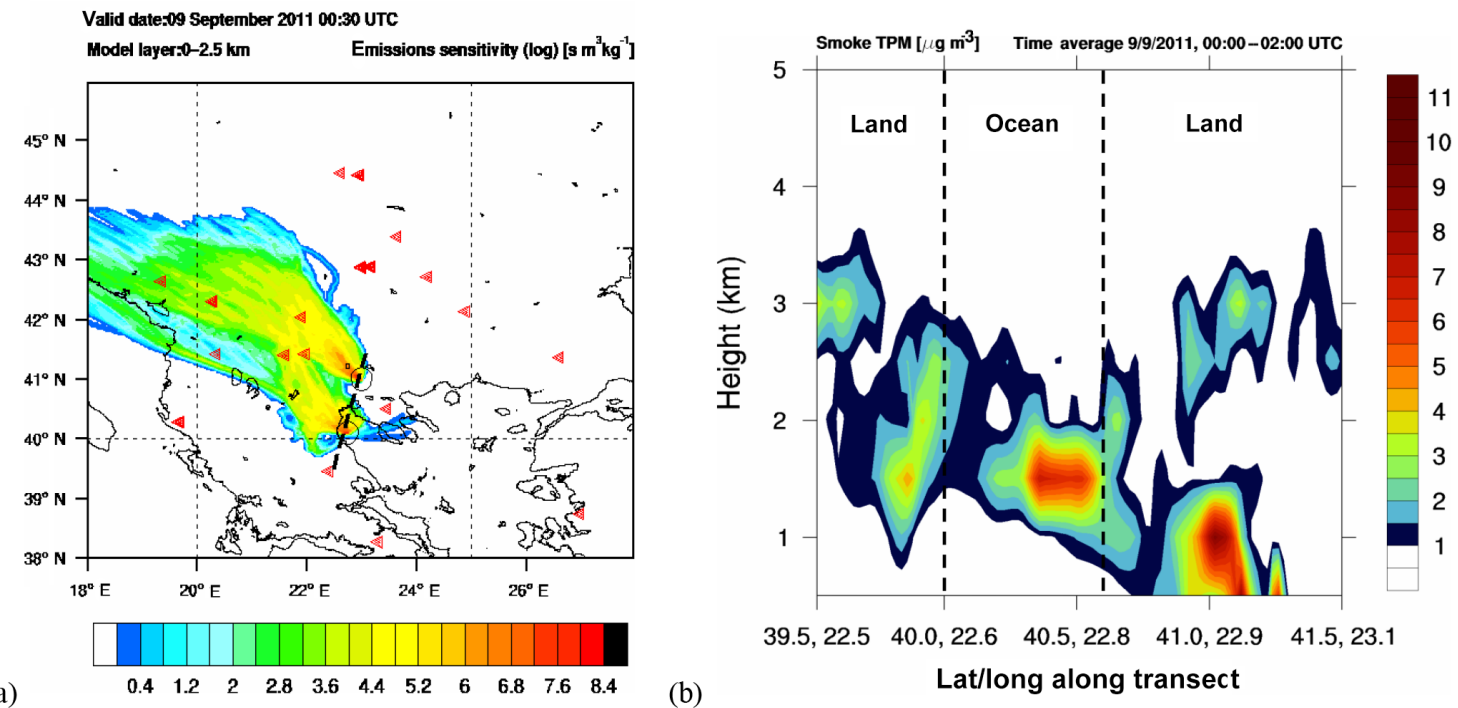

Figure 9. (a) Twenty-four-hour emission sensitivity (in logarithmic scale) $\left(\log \left(\mathrm{s} \mathrm{m}^{3} \mathrm{~kg}^{-1}\right)\right.$ ) for particles that originate from the first $2.5 \mathrm{~km}$ of the FLEXPART-WRF model and are observed on 9 September 2011, 00:30 UTC, at heights between 1 and $4 \mathrm{~km}$ above land and ocean in the Thessaloniki area. The red triangles indicate MODIS hot spot locations during that period. (b) Cross section of $2 \mathrm{~h}$ average concentration of smoke TPM $\left(\mu \mathrm{g} \mathrm{m}^{-3}\right)$ predicted with the dispersion model forward simulations along the FAAM BAe-146 flight on 9 September 2011 , 00:00-02:00 UTC, indicated with the dashed black line in (a).

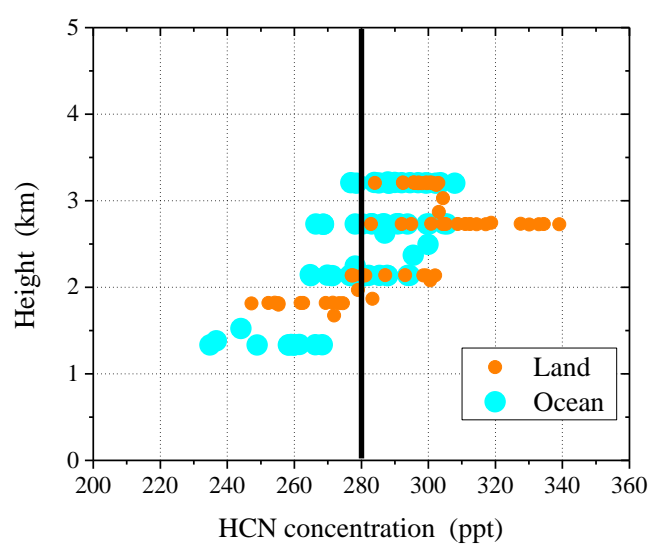

Figure 10. HCN concentration during the FAAM BAe-146 flight above Thessaloniki, Greece, on 9 September 2011, at 00:4801:50 UTC. The data are marked for the flight path above land (orange circles) and ocean (light blue circles). The black line at $280 \mathrm{ppt}$ marks the biomass burning plume threshold detection, equal to 6 standard deviations of the median background HCN concentration (Le Breton et al., 2013).

Although the CALIPSO L2 aerosol classification product identifies the smoke over Thessaloniki city (at the land part of the flight), it seems that at the southern part of the scene, above ocean, the algorithm misclassifies the layers almost completely (Fig. 7c). We believe that this is partly due to the different classification criteria for smoke above land vs. above ocean, as these are defined by Omar et al. (2009) for the CALIPSO classification scheme. More specifically, as can be seen in Fig. 2 in Omar et al. (2009) the non-depolarizing aerosol plumes are classified as smoke plumes above ocean only if they are "elevated layers" (a layer is considered "elevated" when the layer base $>2.5 \mathrm{~km}$ or if $0.5 \mathrm{~km}<$ base $<2.5 \mathrm{~km}$ then top $>4 \mathrm{~km}$ or depth $>2 \mathrm{~km}$; J. Tackett, personal communication, 2013). More analysis on the CALIPSO "hard limit" that can be potentially imposed on the aerosol classification at coastal areas due to the different land/ocean classification criteria can be found in the work of Kanitz et al. (2014). Due to this discontinuity we decided to perform our analysis at the land and ocean parts separately in order to examine the possible differences present in CALIPSO L2 product. For the ocean retrieval we use the area from 40 to $40.6^{\circ}$ latitude (marked with the light blue rectangle in Fig. 7c), whereas for land we use only the two cloud-free $5 \mathrm{~km}$ segments (corresponding to CALIPSO L2 $5 \mathrm{~km}$ profiles) indicated with the orange rectangle in Fig. $7 \mathrm{c}$, in the area from 40.6 to $41.2^{\circ}$ latitude.

\subsection{Flight above land}

Using the combination of airborne in situ and active remote sensing measurements with the IRRA retrieval scheme described in Sect. 2.1, we retrieve profiles of the ambient particle properties above land and ocean. For the retrieval above land we use the lidar measurements taken at $5 \mathrm{~km}$ and the in situ measurements acquired during the SLRs at 3.2, 2.7 and $1.8 \mathrm{~km}$. The comparisons between the measured and calculated dry and ambient particle optical properties show both excellent agreement (Fig. 11 and Table D1 in Appendix D), 

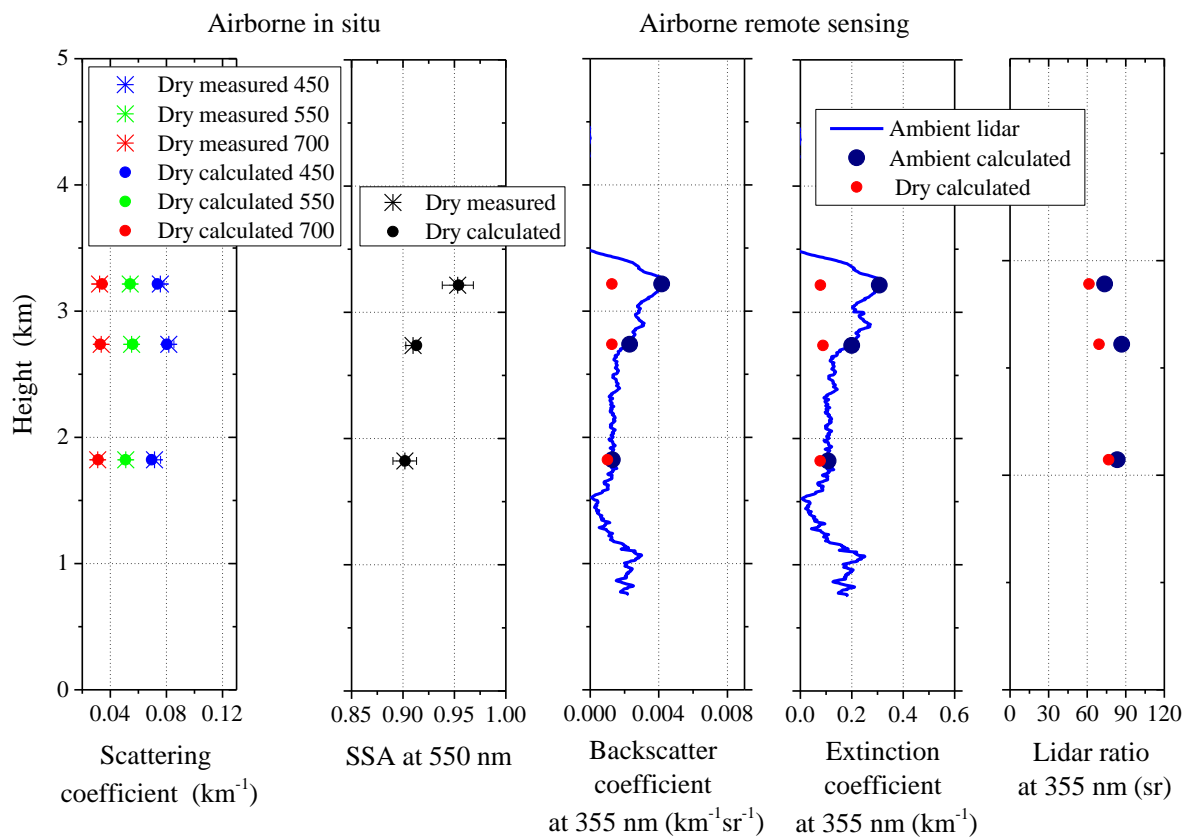

Figure 11. Airborne in situ and remote sensing optical properties, along with the corresponding IRRA-calculated optical properties. From left to right: scattering coefficients at 450,550 and $700 \mathrm{~nm}$ from TSI Integrating Nephelometer (blue, green and red stars for measurements and dots for calculations), SSA at $550 \mathrm{~nm}$ from PSAP and TSI Integrating Nephelometer (black stars for measurements and dots for calculations), backscatter and extinction coefficients at $355 \mathrm{~nm}$ retrieved from the lidar measurements (blue line), along with the corresponding calculated optical properties for dry and ambient particles (red and dark blue dots, respectively), and the calculated lidar ratio at $355 \mathrm{~nm}$ for dry and ambient particles. The data refer to the flight segment above land, above Thessaloniki, Greece, on 9 September 2011 at 00:20-01:42 UTC. The error bars in the first two plots denote the spatial variability of the measurements during each SLR rather than instrumental uncertainty. The calculated optical properties corresponding to the in situ measurements are calculated with truncated size distributions at $1.5 \mu \mathrm{m}$, whereas for the remote sensing calculations the size distributions are not truncated.

with the relative differences to be below $5 \%$. The only exception is the lidar extinction coefficient at $1.8 \mathrm{~km}$, with $\sim 10 \%$ relative difference. This may be due to the incoherence of the lidar and in situ measurements there, due to temporal variability of the atmospheric properties (the lidar measurements are an an average of the flight segment at $\sim 5 \mathrm{~km}$ between 00:20 and 00:27 UTC, whereas the in situ measurements at $1.8 \mathrm{~km}$ refer at 01:38 to 01:42 UTC; see Fig. 6b).

Overall, as seen in Figs. 11 and 12, the very high RHs that exceed $90 \%$ at $3.2 \mathrm{~km}$ and $80 \%$ at $2.7 \mathrm{~km}$ (see Fig. 8) have a large hydration effect on the ambient particle optical and microphysical properties. Figure 11 shows quite vividly the hydration effect on the ambient backscatter and extinction coefficients at $355 \mathrm{~nm}$, at 2.7 and $3.2 \mathrm{~km}$, whereas at $1.8 \mathrm{~km}$ the effect is small. The comparison of dry (red dots) with ambient calculations (blue dots) for the backscatter and extinction coefficients highlights the deficiency of dry in situ measurements to reproduce the ambient particle optical properties in humid conditions.

A similar conclusion can be drawn from the retrieved ambient (number and volume) size distributions provided in Fig. 12 and Table 3 and the respective refractive indices in Table 4 . The hydration effect of both fine and coarse modes is notable, especially for the high-RH layers at 2.7 and $3.2 \mathrm{~km}$, with a water content of 55 and $80 \%$ of the total volume, respectively. The retrieved dry particle fine mode is well-fitted to the measured PCASP and GRIMM data, with $95 \%$ of the calculated size distribution data points to be within two error bars of the measured data. For the coarse mode the fit is also acceptable, although the high uncertainty in the in situ measurements does not allow a definite conclusion.

The retrieved ambient LR at $355 \mathrm{~nm}$ of $\sim 70-90 \mathrm{sr}$ and the dry single scattering albedo (SSA) at $550 \mathrm{~nm}$ of $\sim 0.9$ 0.95 (Fig. 11) indicate the presence of absorbing particles along the flight path, in good agreement with the sourcereceptor simulations as well as with the $\mathrm{HCN}$ and $\mathrm{CO}$ airborne in situ measurements, all showing the advection of smoke over Thessaloniki area. The retrieved geometric mean radius and standard deviation of the fine mode are similar to measurements detailed in Johnson et al. (2016) for the SAMBBA, DABEX and SAFARI-2000 campaigns for aged smoke. The retrieved dry particle refractive indices of $1.54-1.6+i 0.008-0.021$ are within the range of typical values for biomass burning particles, and the corresponding ambient refractive indices $(1.38-1.55+i 0.002-0.019)$ are close to the AERONET 8-year global aerosol climatol- 
Table 3. Retrieved number size distribution parameters of dry and ambient particles, for the retrieval above land. The total number concentrations and geometric standard deviations are the same for dry and ambient particles.

\begin{tabular}{|c|c|c|c|c|c|c|}
\hline \multirow[b]{2}{*}{$\begin{array}{l}\text { Height } \\
(\mathrm{km})\end{array}$} & \multicolumn{3}{|c|}{ Dry particles } & \multicolumn{3}{|c|}{ Ambient particles } \\
\hline & $\begin{array}{l}\text { Total number } \\
\text { concentrations } \\
N_{\mathrm{d}_{\mathrm{f}}}, N_{\mathrm{d}_{\mathrm{c}}} \\
\left(\mathrm{cm}^{-3}\right)\end{array}$ & $\begin{array}{l}\text { Geometric } \\
\text { mean radii } \\
r_{\mathrm{md}_{\mathrm{f}}}, r_{\mathrm{md}_{\mathrm{c}}} \\
(\mu \mathrm{m})\end{array}$ & $\begin{array}{l}\text { Geometric } \\
\text { standard } \\
\text { deviations } \\
\sigma_{\mathrm{d}_{\mathrm{f}}}, \sigma_{\mathrm{d}_{\mathrm{c}}}\end{array}$ & $\begin{array}{l}\text { Total number } \\
\text { concentrations } \\
N_{\mathrm{a}_{\mathrm{f}}}, N_{\mathrm{a}_{\mathrm{c}}} \\
\left(\mathrm{cm}^{-3}\right)\end{array}$ & $\begin{array}{l}\text { Geometric } \\
\text { mean radii } \\
r_{\mathrm{ma}_{\mathrm{f}}}, r_{\mathrm{ma}_{\mathrm{c}}} \\
(\mu \mathrm{m})\end{array}$ & $\begin{array}{l}\text { Geometric } \\
\text { standard } \\
\text { deviations } \\
\sigma_{\mathrm{a}_{\mathrm{f}}}, \sigma_{\mathrm{a}_{\mathrm{c}}}\end{array}$ \\
\hline 3.2 & $778,0.7$ & $0.1,0.7$ & $1.5,1.6$ & $778,0.7$ & $0.2,1.1$ & $1.5,1.6$ \\
\hline 2.7 & $1317,0.9$ & $0.1,0.5$ & $1.5,1.9$ & $1317,0.9$ & $0.1,0.7$ & $1.5,1.9$ \\
\hline 1.8 & $726,0.8$ & $0.1,0.4$ & $1.4,1.9$ & $726,0.8$ & $0.1,0.5$ & $1.4,1.9$ \\
\hline
\end{tabular}
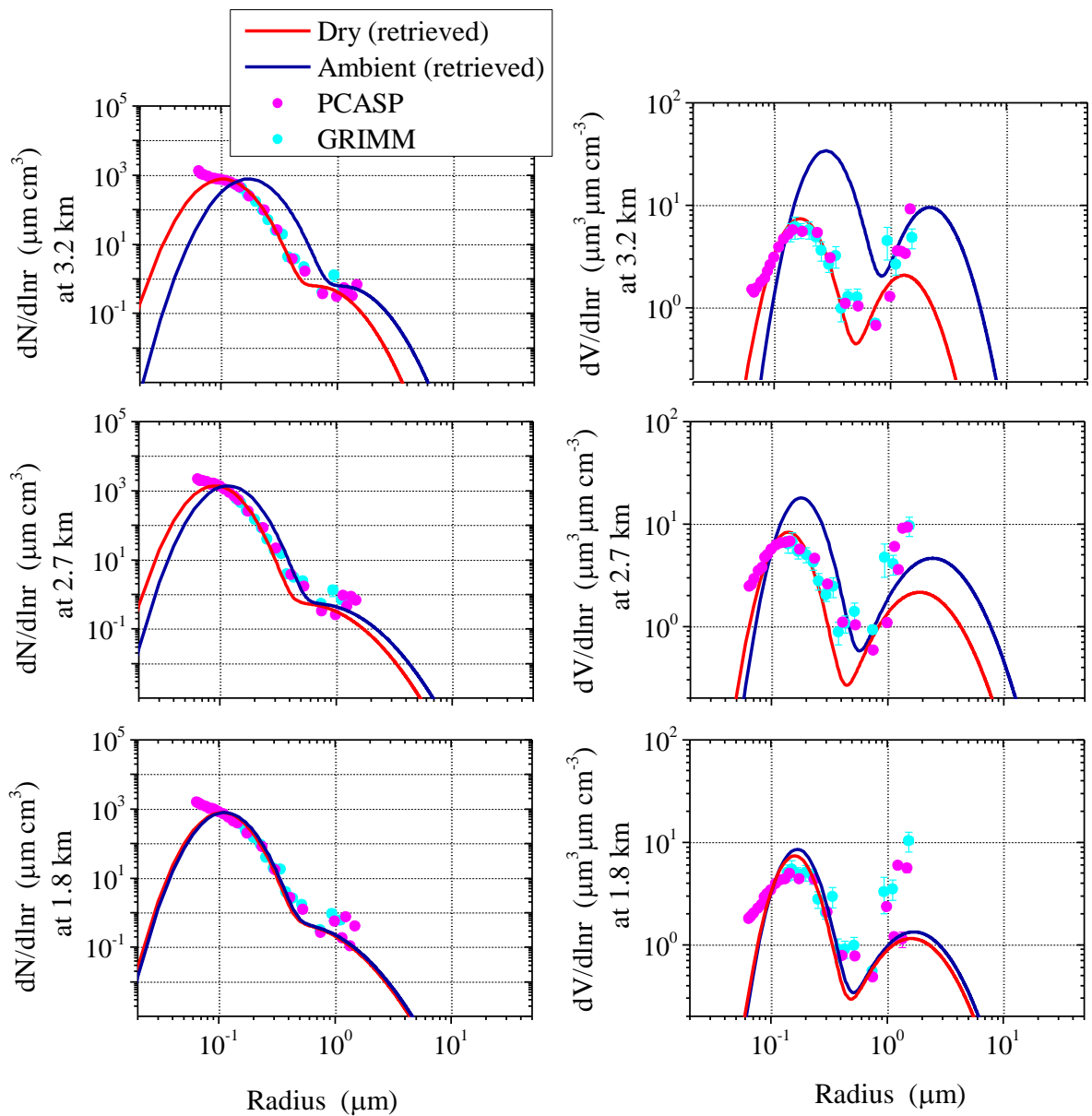

Figure 12. Retrieved number (left) and volume (right) size distributions along with the airborne in situ measurements from PCASP and GRIMM OPCs at the altitudes of 1.8, 2.7 and $3.2 \mathrm{~km}$. The red line denotes the dry particles and the blue line the ambient particles. The PCASP and GRIMM size distributions are truncated at $1.5 \mu \mathrm{m}$, showing the effect of the inlets in the sampled volume. The data refer to the flight segment above land, above Thessaloniki, Greece, on 9 September 2011 at 00:56-01:42 UTC.

ogy of Dubovik et al. (2002). More specifically, Dubovik et al. (2002) report a range of $1.47 \pm 0.03$ to $1.52 \pm 0.01$ for the real part and $0.00093 \pm 0.003$ to $0.021 \pm 0.004$ for the imaginary part.

\subsection{Flight above ocean}

For the IRRA retrieval above ocean we use the airborne lidar measurements at $5 \mathrm{~km}$ and the in situ measurements from the SLRs at 3.2, 2.7, 2.1 and $1.3 \mathrm{~km}$. The calculated optical properties reproduce well the measurements, as shown in Fig. 13 

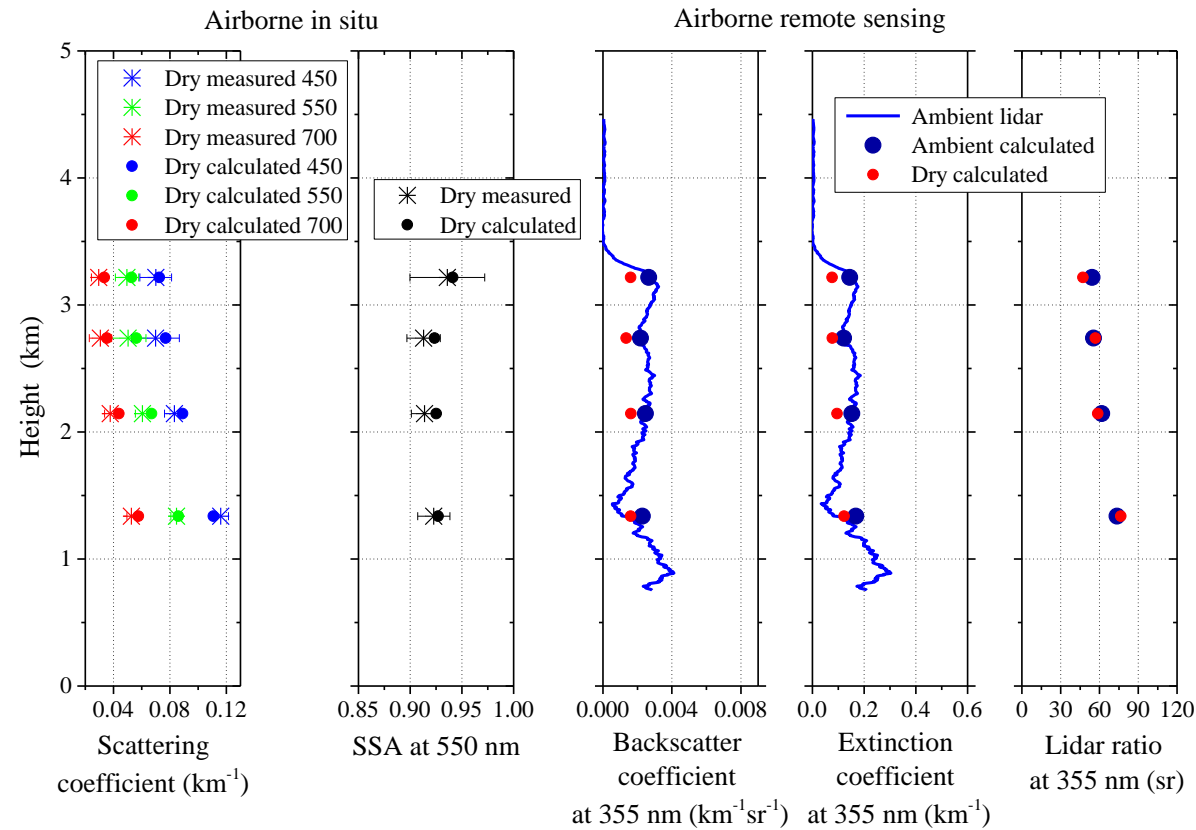

Figure 13. As for Fig. 11, for the flight segment above ocean, above Thessaloniki, on 9 September 2011 at 00:06-01:50 UTC.

Table 4. Retrieved refractive indices of dry and ambient particles for the IRRA retrieval above land.

\begin{tabular}{lrr}
\hline Height $(\mathrm{km})$ & \multicolumn{2}{c}{ Retrieved refractive index } \\
\hline & Dry particles & Ambient particles \\
\hline 3.2 & $1.54+i 0.008$ & $1.38+i 0.002$ \\
2.7 & $1.60+i 0.018$ & $1.46+i 0.008$ \\
1.8 & $1.58+i 0.021$ & $1.55+i 0.019$ \\
\hline
\end{tabular}

(and in Table D2 of Appendix D), with most of the relative differences to be below $15 \%$. For the lidar backscatter and extinction coefficients at the lower SLRs at 2.1 and $1.3 \mathrm{~km}$ these differences are larger and range at $\sim 30-100 \%$. As explained for the retrieval above land as well, this may be due to the temporal variability of the atmosphere, resulting in the lidar seeing a different aerosol plume than the in situ measurements, especially for the lower SLRs (see Fig. 6b).

The results support the presence of smoke mixed with other aerosol types (e.g., urban pollution), with the ambient LR at $355 \mathrm{~nm}$ to be $\sim 55-75 \mathrm{sr}$ and the dry particle SSA at $550 \mathrm{~nm}$ to be $\sim 0.9-0.95$. Figure 14 and Table 5 show the retrieved (number and volume) size distributions of dry and ambient particles, at different altitudes and Table 6 shows the corresponding refractive indices. As with the land retrieval, the PCASP and GRIMM fine mode measurements are well-fitted, whereas for the coarse mode the uncertainty is higher. The hydration effect is mostly obvious at $3.2 \mathrm{~km}$ (RH of $\sim 80 \%$ with $40 \%$ water content in the particle total volume), whereas it is very small at $1.3 \mathrm{~km}(\mathrm{RH}$ at $\sim 55 \%$ ).
The retrieved geometric mean radius and standard deviation of the fine mode are smaller than the values reported in Johnson et al. (2016), indicating mixing with finer aerosol (e.g., urban pollution). The retrieved dry refractive indices of $\sim 1.50-1.66+i 0.01-0.019$ have similar values with the retrieved refractive indices above land, although the real part of 1.66 at $2.7 \mathrm{~km}$ is higher. Moreover, the ambient refractive index values of $\sim 1.48-1.6+i 0.006-0.015$ are comparable to AERONET climatological values (Dubovik et al., 2002), indicating the smoke particle presence above the ocean as well.

\subsection{Comparison with CALIPSO L2 product}

Using the retrieved ambient size distribution and refractive index at different altitudes we calculate the ambient backscatter, extinction coefficient and lidar ratio at $532 \mathrm{~nm}$ and compare them with the corresponding CALIPSO L2 products. Above land, the smoke layer at $\sim 2-3.5 \mathrm{~km}$ is correctly identified by the CALIPSO aerosol classification scheme (Fig. 7c), and a prescribed LR at $532 \mathrm{~nm}$ of $70 \mathrm{sr}$ (assigned for smoke particles) is used for the CALIPSO L2 backscatter and extinction coefficient retrievals. Figure 15 presents the results for the above-land retrieval, showing good agreement with the CALIPSO L2 product. The small differences seen are within the spatial variability and can be due to the time difference of CALIPSO overpass (at 00:31 UTC) and the longer FAAM BAe-146 flight (at 00:0501:45 UTC). The LRs at $532 \mathrm{~nm}$ calculated with the retrieved ambient size distributions and refractive indices are 70-80 sr, supporting the presence of the smoke particles. The optical 
Table 5. Same as Table 3, for the retrieval above ocean.

\begin{tabular}{|c|c|c|c|c|c|c|}
\hline \multirow[b]{2}{*}{$\begin{array}{l}\text { Height } \\
(\mathrm{km})\end{array}$} & \multicolumn{3}{|c|}{ Dry particles } & \multicolumn{3}{|c|}{ Ambient particles } \\
\hline & $\begin{array}{l}\text { Total number } \\
\text { concentrations } \\
N_{\mathrm{d}_{\mathrm{f}}}, N_{\mathrm{d}_{\mathrm{c}}} \\
\left(\mathrm{cm}^{-3}\right)\end{array}$ & $\begin{array}{l}\text { Geometric } \\
\text { mean radii } \\
r_{\mathrm{md}_{\mathrm{f}}}, r_{\mathrm{md}_{\mathrm{c}}} \\
(\mu \mathrm{m})\end{array}$ & $\begin{array}{l}\text { Geometric } \\
\text { standard } \\
\text { deviations } \\
\sigma_{\mathrm{d}_{\mathrm{f}}}, \sigma_{\mathrm{d}_{\mathrm{c}}}\end{array}$ & $\begin{array}{l}\text { Total number } \\
\text { concentrations } \\
N_{\mathrm{a}_{\mathrm{f}}}, N_{\mathrm{a}_{\mathrm{c}}} \\
\left(\mathrm{cm}^{-3}\right)\end{array}$ & $\begin{array}{l}\text { Geometric } \\
\text { mean radii } \\
r_{\mathrm{ma}_{\mathrm{f}}}, r_{\mathrm{ma}_{\mathrm{c}}} \\
(\mu \mathrm{m})\end{array}$ & $\begin{array}{l}\text { Geometric } \\
\text { standard } \\
\text { deviations } \\
\sigma_{\mathrm{a}_{\mathrm{f}}}, \sigma_{\mathrm{a}_{\mathrm{c}}}\end{array}$ \\
\hline 3.2 & $2814,0.2$ & $0.05,1.6$ & $1.8,1.4$ & $2814,0.2$ & $0.06,1.9$ & $1.8,1.4$ \\
\hline 2.7 & $1500,0.6$ & $0.08,0.6$ & $1.5,2.4$ & $1500,0.6$ & $0.08,0.6$ & $1.5,2.4$ \\
\hline 2.1 & $1833,0.6$ & $0.08,1.3$ & $1.6,1.8$ & $1833,0.6$ & $0.08,1.4$ & $1.6,1.8$ \\
\hline 1.3 & $1427,0.4$ & $0.1,1.1$ & $1.6,1.6$ & $1427,0.4$ & $0.1,1.1$ & $1.6,1.6$ \\
\hline
\end{tabular}
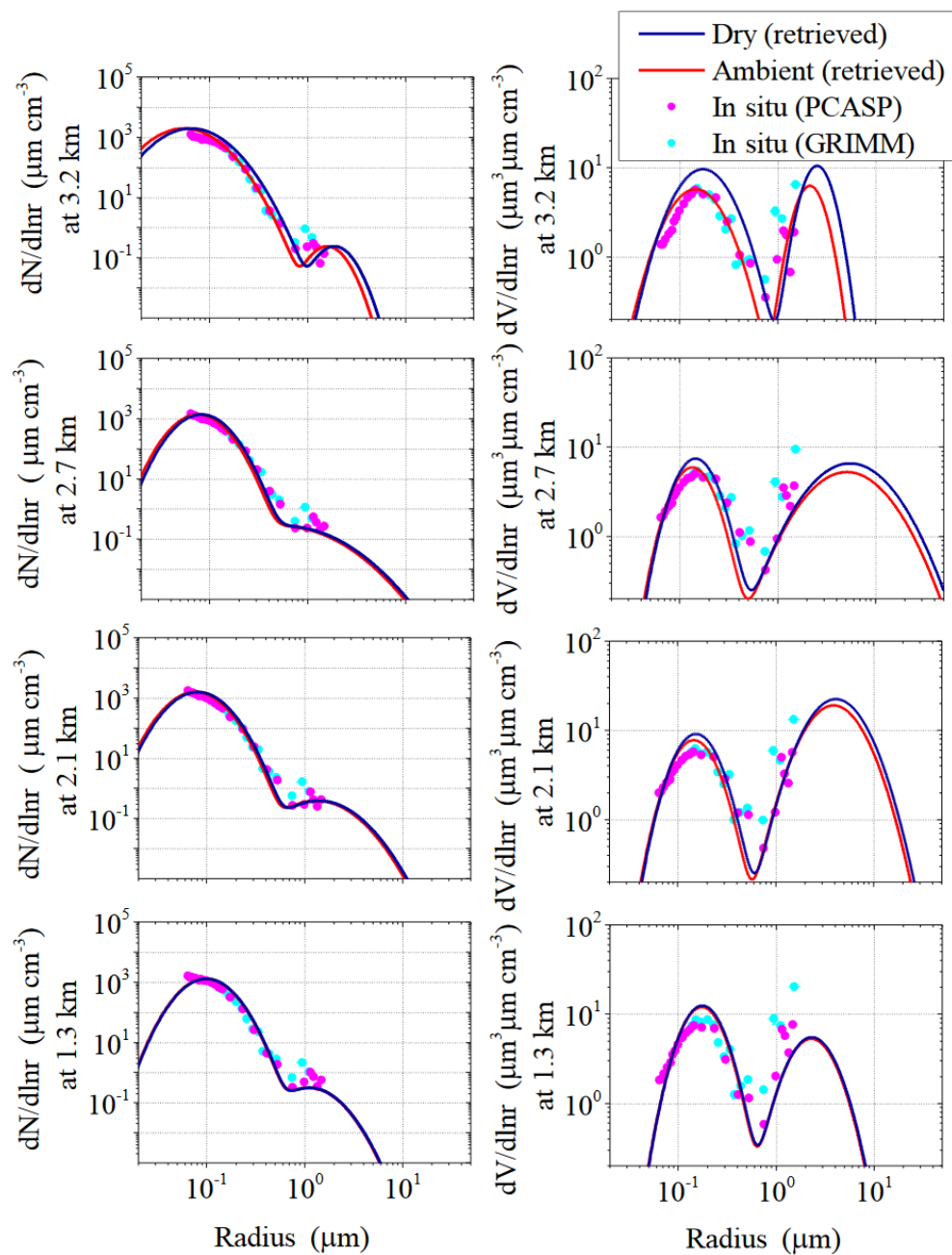

Figure 14. As for Fig. 12, for the flight segment above ocean, above Thessaloniki, on 9 September 2011 at 00:45-01:50 UTC.

properties are calculated also using the dry particle size distribution and refractive index (red circles in Fig. 15) to highlight the problems that arise when using dry in situ measurements for satellite validation for cases of high RH.

Over the ocean the retrieved ambient LRs at $532 \mathrm{~nm}$ at $\sim 60-75 \mathrm{sr}$ are lower than over land, indicating smoke particles mixed with other aerosol types. CALIPSO detects the aerosols correctly but does not classify them as smoke (except only for one $5 \mathrm{~km}$ profile); as shown in Fig. 7c, it classifies the particles either as polluted dust $(\mathrm{LR}=65 \mathrm{sr})$, polluted continental ( $\mathrm{LR}=70 \mathrm{sr}$ ) or marine aerosol $(\mathrm{LR}=20 \mathrm{sr})$, resulting in variable and lower LRs $(25-70 \mathrm{sr})$. The mean LR is close to $60 \mathrm{sr}$, and thus the mean backscatter and extinction coefficients are not excessively affected by this misclassifica- 
Table 6. Same as Table 4, for the retrieval above ocean.

\begin{tabular}{lrr}
\hline Height $(\mathrm{km})$ & \multicolumn{2}{c}{ Retrieved refractive index } \\
\hline & Dry particles & \multicolumn{1}{c}{ Ambient particles } \\
\hline 3.2 & $1.59+i 0.01$ & $1.48+i 0.006$ \\
2.7 & $1.66+i 0.019$ & $1.6+i 0.015$ \\
2.1 & $1.59+i 0.015$ & $1.56+i 0.013$ \\
1.3 & $1.50+i 0.015$ & $1.50+i 0.014$ \\
\hline
\end{tabular}
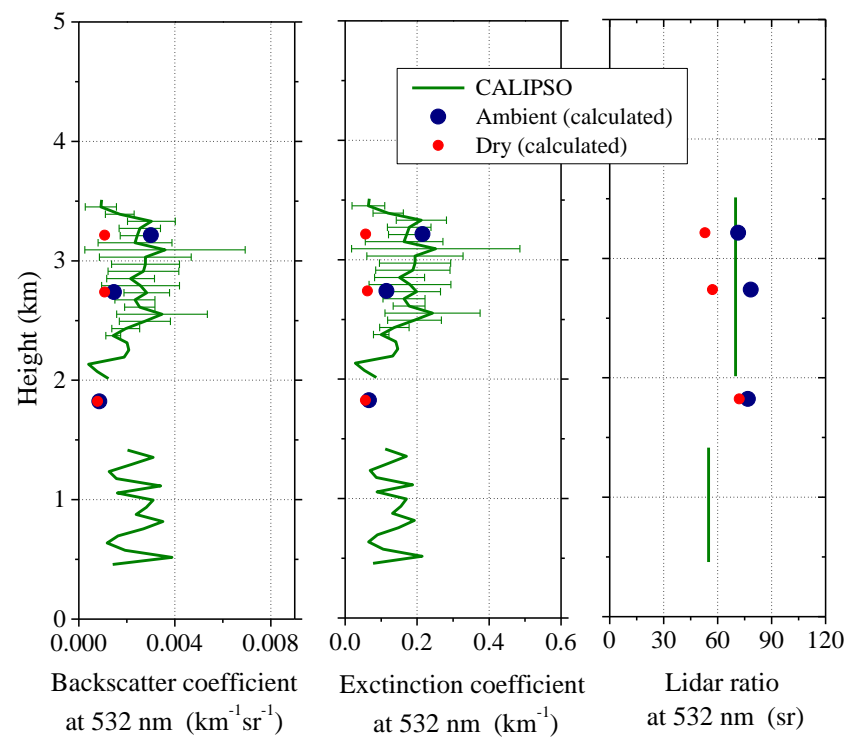

Figure 15. Backscatter coefficient (left), extinction coefficient (middle) and LR (right) at $532 \mathrm{~nm}$, calculated from the IRRAretrieved ambient particle properties during the FAAM BAe-146 flight above land (dark blue circles), and provided by the CALIPSO L2 product (green line) for the CALIPSO overpass above Thessaloniki, Greece, on 9 September 2011 at 00:31 UTC. The error bars in CALIPSO profiles denote the spatial variability and not the uncertainty of the CALIPSO L2 product. The calculated dry particle optical properties are also shown with red circles.

tion. The CALIPSO misclassification is due to the constraint applied in the algorithm to identify only the elevated layers as smoke layers above the ocean.

\subsection{Scattering growth factor}

The enhancement of aerosol scattering due to the hygroscopic growth is shown in Fig. 17 with the scattering growth factor at $532 \mathrm{~nm}$. The scattering growth factor is the ratio of the ambient aerosol scattering coefficient, to the dry aerosol scattering coefficient. Figure 17 shows that the scattering at $\mathrm{RH}=94 \%$ is almost 4 times larger than in the dry state. These values fall within the range of Köhler curves for aged smoke particles and can be used in climate models for the estimation of hydrated aged smoke particle scattering (e.g., Johnson et al., 2016).
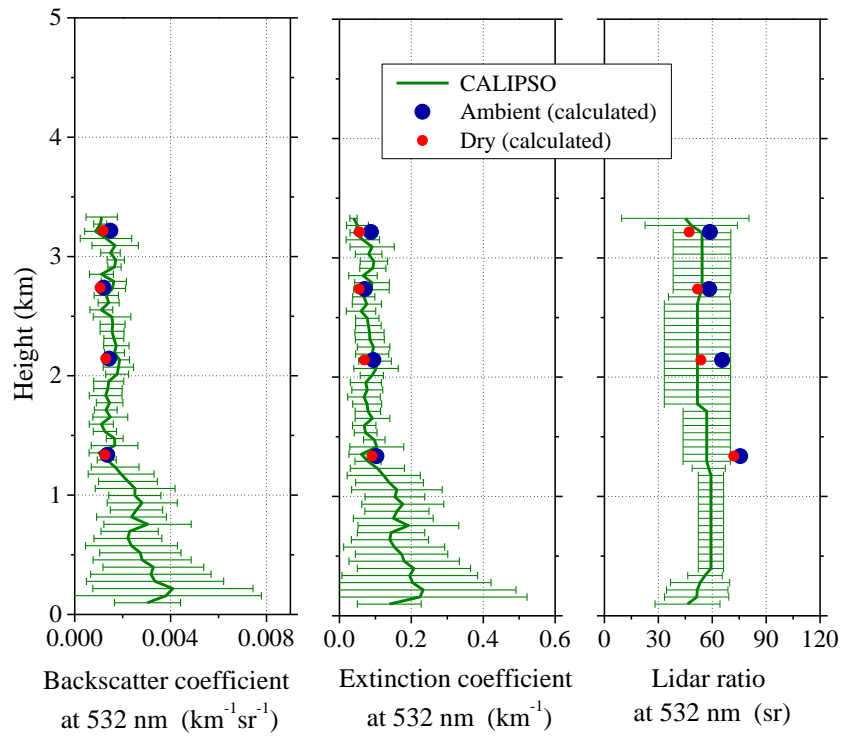

Figure 16. As for Fig. 15, for the flight segment above the ocean.

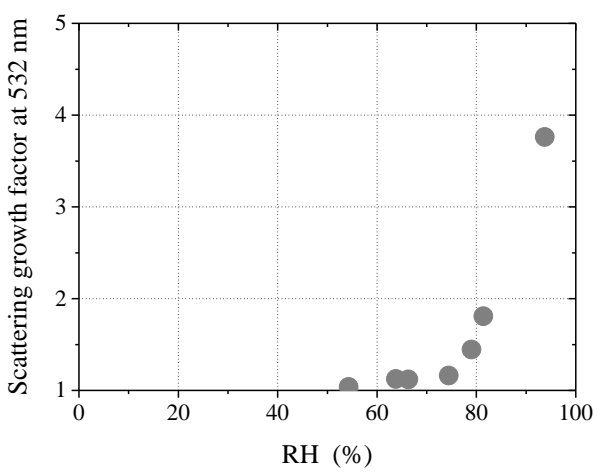

Figure 17. The scattering growth factor at $532 \mathrm{~nm}$, acquired from the retrieved aerosol microphysical properties during the ACEMED campaign, above Thessaloniki, on 9 September 2011.

\section{Discussion}

The results presented here are very encouraging for the IRRA retrieval scheme performance. First, IRRA succeeds to reproduce both dry in situ and ambient remote sensing measurements, even in humid conditions of RH $>80-90 \%$, by considering both dry and ambient particle states in the retrieval scheme and by effectively modeling the particle hygroscopic growth with the ISORROPIA II model. Second, IRRA manages to provide the complete set of the particle microphysical properties, overcoming the deficiencies in the in situ measurements due to the insufficient coarse mode size distribution and chemical composition sampling. We do not claim that the coarse mode retrieval is highly accurate with IRRA, but at least it closely reproduces the measurements and provides similar results to the climatological values of biomass burning particles for the smoke plume case we analyzed here. 
A more complete set of inputs, as in situ coarse mode sampling and multi-wavelength lidar measurements, should increase the retrieval input information content and provide more accurate results. Third, IRRA retrieval is not gravely affected by possible uncertainties in the in situ measured microphysical properties, since these are only used as a first guess in the iterative retrieval scheme. The unknown coarse mode chemical composition is an exception, since it directly affects the estimation of the coarse mode hygroscopic growth in the ISORROPIA II model.

\section{Conclusions}

IRRA utilizes successfully the airborne active remote sensing and in situ measurements in order to provide a consistent characterization of the ambient aerosol at different altitudes, using typical airborne instruments employed by the FAAM BAe-146 aircraft flight. The retrieved ambient properties found to be mostly consistent also with the collocated CALIPSO L2 product. Specifically, smoke plumes are identified along the flight path, which are detected from CALIPSO classification scheme above land but not above ocean.

One of the main shortfalls of the case analyzed here is the large uncertainty in the airborne in situ measurements regarding the coarse particle size distribution and chemical composition. In future IRRA applications, in situ particle sizers achieving high accuracy measurements of the coarse mode should be employed, along with filter sampling of the coarse particles. We should note though that, despite the limited coarse mode information, our retrieval provides plausible results for the coarse particles for the case presented here.

The achievement of IRRA is the overall successful profiling of the ambient aerosol microphysical, optical and hygroscopic properties utilizing the combination of dry particle property measurements, active remote sensing and ISORROPIA II hygroscopic growth modeling, all in one retrieval scheme. The potential of IRRA lies beyond the case study analyzed here, providing an effective aerosol characterization in ambient conditions of high importance for aerosol/cloud interaction, radiative transfer and climate studies.

We should highlight that IRRA is optimized with the measurement set acquired during the ACEMED campaign, but this is not a limiting factor of its applicability. The basic concept of combining vertically resolved in situ and active remote sensing measurements can be satisfied using a different measurement strategy as well. For example, after applying minor changes, IRRA can combine vertically resolved in situ measurements from aircraft or less-costly unmanned aerial vehicle platforms with ground-based or satellite lidar measurements.

IRRA can also be developed further in the future to include ground-based or airborne polarization measurements which should help to decrease the aerosol retrieval uncertainty, especially for the particle refractive index (Mishchenko and
Travis, 1997). Another feature we plan to implement is the retrieval of non-spherical particle properties, employing nonspherical particle scattering codes in the algorithm (e.g., the T-matrix code as in Dubovik et al., 2006, or the Advanced Discrete Dipole Approximation as in Gasteiger et al., 2011). This will extend the applicability of IRRA to dust particle characterization as well.

For the application presented here, it has been shown that it is feasible with IRRA to evaluate space-borne profiling measurements. Beyond CALIPSO, IRRA can be further applied for the validation of the new NASA CATS mission but also future ESA missions like ADM-Aeolus and EarthCARE.

\section{Data availability}

The FAAM core data along with the Leosphere ALS450 lidar, the AMS and the CIMS data products are available through the EUFAR project archive on the BADC http://catalogue.ceda.ac.uk/uuid/ f014fe1ff19f40d78c83223458d82aee (FAAM, 2016). Raw data are available on request. The CALIPSO data were obtained from the online archive of ICARE Data and Services center http://www.icare.univ-lille1.fr/archive (CALIPSO Science Team, 2015a, b; ICARE Data Center, 2016). The MODIS Active Fire Detections data were obtained by NASA FIRMS (https://earthdata.nasa.gov/active-fire-data) (NASA FIRMS, 2016). The final analysis (FNL) data were obtained by the National Centers for Environmental Prediction/National Weather Service/NOAA/US Department of Commerce (https://doi.org/10.5065/D6FB50XD) (NCEP FNL, 1997). The sea surface temperature (SST) data were obtained by the NOAA/OAR/ESRL PSD, Boulder, Colorado, USA, from their web site at http://www.esrl.noaa.gov/psd// (NOAA/OAR/ESRL PSD, 2016). 


\section{Appendix A: IRRA optimization retrieval scheme}

IRRA retrieval methodology shown in Fig. 1 is automated utilizing the nonlinear least-squares solver "lsqcurvefit" of MATLAB. The lsqcurvefit calculates the dry and ambient particle size distributions and refractive indices that minimize the difference between the calculated and measured optical properties in a least-squares sense (Eq. A1).

$$
\begin{aligned}
& \min \left\|\boldsymbol{F}\left(\boldsymbol{S} \boldsymbol{D}_{\boldsymbol{d}}, m_{\mathrm{d}}, f_{\mathrm{g}_{\mathrm{f}, \mathrm{c}}}, f_{\mathrm{w}_{\mathrm{f}, \mathrm{c}}}\right)-\boldsymbol{y}\right\|_{2}^{2} \\
& =\min \sum_{i}\left(F\left(\boldsymbol{S} \boldsymbol{D}_{\boldsymbol{d}}, m_{\mathrm{d}}, f_{\mathrm{g}_{\mathrm{f}, \mathrm{c}}}, f_{\mathrm{w}_{\mathrm{f}, \mathrm{c}}}\right)_{i}-y_{\mathrm{i}}\right)^{2} \\
& \boldsymbol{y}= \\
& \quad\left\{\mathrm{sc}_{450}, \mathrm{sc}_{550}, \mathrm{sc}_{700}, \mathrm{abs}_{565}, \alpha_{355}, \beta_{355}, \mathrm{NC}_{0.8}, \mathrm{NC}_{1.1}\right\}
\end{aligned}
$$

$$
\begin{aligned}
& \boldsymbol{F}\left(\boldsymbol{S} \boldsymbol{D}_{\boldsymbol{d}}, m_{\mathrm{d}}, f_{\mathrm{g}_{\mathrm{f}, \mathrm{c}}}, f_{\mathrm{w}_{\mathrm{f}, \mathrm{c}}}\right)= \\
& \left\{\begin{array}{l}
F_{\mathrm{sc} 450}\left(\boldsymbol{S} \boldsymbol{D}_{\boldsymbol{d}}, m_{\mathrm{d}}\right) \\
F_{\mathrm{sc}_{550}}\left(\boldsymbol{S} \boldsymbol{D}_{\boldsymbol{d}}, m_{\mathrm{d}}\right), F_{\mathrm{sc} 700}\left(\boldsymbol{S} \boldsymbol{D}_{\boldsymbol{d}}, m_{\mathrm{d}}\right) \\
F_{\mathrm{abs} 565}\left(\boldsymbol{S} \boldsymbol{D}_{\boldsymbol{d}}, m_{\mathrm{d}}\right) \\
F_{\alpha_{355}}\left(\boldsymbol{S} \boldsymbol{D}_{\boldsymbol{d}}, m_{\mathrm{d}}, f_{\mathrm{g}_{\mathrm{f}, \mathrm{c}}}, f_{\mathrm{w}_{\mathrm{f}, \mathrm{c}}}\right) \\
F_{\beta_{355}}\left(\boldsymbol{S} \boldsymbol{D}_{\boldsymbol{d}}, m_{\mathrm{d}}, f_{\mathrm{g}_{\mathrm{f}, \mathrm{c}}}, f_{\mathrm{w}_{\mathrm{f}, \mathrm{c}}}\right) \\
F_{\mathrm{NC}_{0.8}}\left(\boldsymbol{S} \boldsymbol{D}_{\boldsymbol{d}}\right), F_{\mathrm{NC}_{1.1}}\left(\boldsymbol{S} \boldsymbol{D}_{\boldsymbol{d}}\right)
\end{array}\right\} \\
& \boldsymbol{S} \boldsymbol{D}_{\boldsymbol{d}}=\left\{r_{\mathrm{md}_{\mathrm{f}}}, \sigma_{\mathrm{d}_{\mathrm{f}}}, N_{\mathrm{d}_{\mathrm{f}}}, r_{\mathrm{md}_{\mathrm{c}}}, \sigma_{\mathrm{d}_{\mathrm{c}}}, N_{\mathrm{d}_{\mathrm{c}}}\right\}
\end{aligned}
$$

The retrieval is performed for each height separately. In Eq. (A1), the summation over " $i$ " denotes the different optical properties, $\boldsymbol{y}$ is the vector of the measured optical properties (Eq. A2) and $\boldsymbol{F}$ is the vector of the calculated optical properties (Eq. A3). $\boldsymbol{S} \boldsymbol{D}_{\boldsymbol{d}}$ is the vector of the dry size distribution parameters (Eq. A4), $m_{\mathrm{d}}$ is the dry particle refractive index and $f_{\mathrm{g}_{\mathrm{f}, \mathrm{c}}}, f_{\mathrm{w}_{\mathrm{f}, \mathrm{c}}}$ are the hygroscopic growth and water volume fraction of fine and coarse ambient particles. The retrieved parameters are the $\boldsymbol{S} \boldsymbol{D}_{\boldsymbol{d}}$ and $m_{\mathrm{d}}$, whereas $f_{\mathrm{g}_{\mathrm{f}, \mathrm{c}}}$ and $f_{\mathrm{w}_{\mathrm{f}, \mathrm{c}}}$ are provided by ISORROPIA II.

The $y$ vector contains the in situ measurements of the scattering coefficients at 450,550 and $700\left(\mathrm{sc}_{450}, \mathrm{sc}_{550}\right.$ and $\mathrm{sc}_{700}$, respectively), the absorption coefficient at $565 \mathrm{~nm}$ (abs565), as well as the lidar measurements of extinction $\left(\alpha_{355}\right)$ and backscatter coefficient at $355 \mathrm{~nm}\left(\beta_{355}\right)$. In order for the retrieval not to be under-constrained, with less measurements than retrieved parameters, $\boldsymbol{y}$ also contains the in situ measured number concentration of dry particles at 0.8 and $1.1 \mu \mathrm{m}$ $\left(\mathrm{NC}_{0.8}\right.$ and $\left.\mathrm{NC}_{1.1}\right)$. We use these coarse particle concentration values to constrain more effectively the coarse mode retrieval, for which the in situ measurements provide accepted accuracy for sizes $<1.5 \mu \mathrm{m}$ (radius) (see discussion in Sect. 2.2.2).

$\boldsymbol{F}$ vector contains the corresponding calculated values of $\boldsymbol{y}: F_{\mathrm{sc}_{450}}, F_{\mathrm{sc}_{550}}, F_{\mathrm{sc}_{700}}$ and $F_{\mathrm{absc}_{565}}$ are the scattering coefficients at 450,550 and $700 \mathrm{~nm}$ and the absorption coefficient at $565 \mathrm{~nm}$, calculated from the dry particle number size distribution $\left(\boldsymbol{S} \boldsymbol{D}_{\boldsymbol{d}}\right)$ and refractive index $\left(m_{\mathrm{d}}\right)$, utilizing Mie scat- tering calculations. Moreover, $F_{\alpha_{355}}$ and $F_{\beta_{355}}$ are the extinction and backscatter coefficients at $355 \mathrm{~nm}$, calculated from the ambient number size distribution (derived from $\boldsymbol{S} \boldsymbol{D}_{\boldsymbol{d}}$ and $f_{\mathrm{g}_{\mathrm{f}, \mathrm{c}}}$, as in Eqs. 2, 3) and refractive index (derived from $m_{\mathrm{d}}$ and $f_{\mathrm{w}_{\mathrm{f}, \mathrm{c}}}$, as in Eqs. 4, 5), with Mie scattering calculations. Finally, $F_{\mathrm{NC}_{0.8}}$ and $F_{\mathrm{NC}_{1.1}}$ are the values of $\boldsymbol{S} \boldsymbol{D}_{\boldsymbol{d}}$ at 0.8 and $1.1 \mu \mathrm{m}$.

The lsqcurvefit function employs the trust-region reflective optimization algorithm (based on the interior-reflective Newton method described in Coleman and Li, 1994, 1996) to minimize the cost function in Eq. (A1). For the first iteration the parameters $\boldsymbol{S} \boldsymbol{D}_{\boldsymbol{d}}$ and $m_{\mathrm{d}}$ are set equal to a first guess, derived from the in situ measurements. Subsequently, the algorithm searches for a set of parameters that minimizes the cost function. The minimization is done using a simpler function (defined by the first two terms of the Taylor approximation of the cost function) which models reasonably well the cost function behavior in a "trust region" around the parameter set. A trial step is then computed by minimizing the modeled function. If the cost function is minimized as well, then the parameter set is updated using the trial step, and the trust region is expanded. Otherwise, the parameter set remains unchanged, the trust region is shrunk and the trial computation is repeated. The optimization procedure stops after predefined stopping criteria are reached. These may include the minimum cost function value, the minimum size of the trial step or a maximum number of iterations. The first two criteria are defined from the input measurement and the retrieved parameter uncertainties, respectively, which are not available for the current analysis. Thus, for the case analyzed here, we used a maximum number of iterations as the stopping criterion.

Moreover, the algorithm has the capability to use constrains for the lower and upper bounds of the retrieved parameters. We utilize this feature for the dry particle fine and coarse mode parameters, so as the retrieved parameters are not very different than the in situ measurements. The dry particle refractive index is also constrained, so as to be within realistic values, with the real part from 1.3 to 1.7 and the imaginary part from 0 to 0.1 . These values cover well the range of values provided from the worldwide aerosol climatology from 8-year AERONET data by Dubovik et al. (2002).

Last, the fitted parameters of $\boldsymbol{y}$ do not have all the same importance for our retrieval. More specifically, we are not interested in reproducing with high accuracy the number concentration measurements at 0.8 and $1.1 \mu \mathrm{m}\left(\mathrm{NC}_{0.8}\right.$ and $\left.\mathrm{NC}_{1.1}\right)$, or at least not as much as the measured optical properties. For this reason we "weight" the fit, by first normalizing to 1 each parameter in $\boldsymbol{y}$ (dividing it with its value) and then multiplying with a weight that is a measure of the importance of the parameter fitting. The same multiplication factors are applied on the parameters of $\boldsymbol{F}$ vector. For the case analyzed here we used weights of 1 for the optical properties and of 0.1 for the number concentrations at 0.8 and $1.1 \mu \mathrm{m}$. The "weighting" of the fit can be very useful in the general case of combining 
measurements of different accuracies and it has been used in other retrievals in the literature (e.g., Dubovik and King, 2000). The weights should be derived based on the measurement accuracy, but if this is not easy to define (as is the case here), even qualitative numbers of "more" or "less" confidence in the measurements can help the retrieval.

\section{Appendix B: Size distribution data handling and calibration}

The number size distribution data from PCASP and GRIMM instruments come in the form of number of particles, per $\mathrm{cm}^{3}$, per size bin. The number concentration for each size bin is normalized by $\mathrm{d} \ln \left(r_{\max }\right)-\mathrm{d} \ln \left(r_{\min }\right)\left(r_{\min }\right.$ and $r_{\max }$ refer to the minimum and maximum bin radius, respectively) to get the log-normal number size distribution $\mathrm{d} N / \mathrm{d} \ln (r)$. The $\log$-normal volume size distribution $\mathrm{d} V / \mathrm{d} \ln (r)$ is then calculated by multiplying $\mathrm{d} N / \mathrm{d} \ln (r)$ with the volume of the particles in each bin.

The data are also inspected for spurious values, using the associated counting error, which for each size bin is defined as the inverse square root of the number of particles in the bin. The data associated with counting errors larger than 0.3 (corresponding to less than three particles in the size bin) are screened out. Moreover, the data are corrected for the refractive index assumption using the true refractive index and calibration standards, with the mieconscat and the cstodconverter software (http://sourceforge.net/projects/mieconscat/ and http://sourceforge.net/projects/cstodconverter/, respectively), as described in Rosenberg et al. (2012). For this correction we assume that the particles are homogeneous and spherical. The uncertainty for the bin width is provided from the cstodconverter software and the uncertainty in the volume of the bin is calculated using the uncertainty in the bin width and the counting uncertainty of each bin.

\section{Appendix C: $\mathbf{R H}$ calculation}

The ambient RH is calculated from the WVSS-II water vapor volume mixing ratio ( $\left.\mathrm{WV}_{\mathrm{VMR}}\right)$ measurements and the ambient pressure $(P)$ measurements as follows:

$\mathrm{RH}=\frac{\mathrm{WV}_{\mathrm{VMR}} P}{e} 100$,

where the $\mathrm{WV}_{\mathrm{VMR}}$ is in $\mathrm{m}^{3} \mathrm{~m}^{-3}, P$ is in $\mathrm{hPa}$ and $e$ (in $\mathrm{hPa}$ ) is the vapor pressure of water calculated from the temperature ( $T$ ) measurements (in $C$ ) as in Lowe and Ficke (1974).

$$
\begin{aligned}
& e= \\
& \begin{array}{l}
a_{0}+T\left(a_{1}+T\left(a_{2}+T\left(a_{3}+T\left(a_{4}+T\left(a_{5}+a_{6} T\right)\right)\right)\right)\right), \\
\text { with } \quad a_{0}=6.107799961,
\end{array} \quad \begin{array}{l}
a_{1}=4.43651852110^{-1}, \\
a_{2}=1.42894580510^{-2},
\end{array} \quad \begin{array}{l}
a_{3}=2.65064847110^{-4}, \\
a_{4}=3.03124039610^{-6}, \\
a_{6}=6.13682092910^{-11} .
\end{array}
\end{aligned}
$$




\section{Appendix D: Measured and retrieved optical properties}

Table D1. Measured vs. IRRA-calculated (bold) in situ measurements of the dry particle scattering coefficient at 450,550 and $700 \mathrm{~nm}$ and SSA at $550 \mathrm{~nm}$, and remote sensing measurements of the ambient backscatter and extinction coefficients at $355 \mathrm{~nm}$, above land. The spatial (horizontal) variability of the measurements is provided as the standard deviation around the mean value.

\begin{tabular}{lllll|ll}
\hline & \multicolumn{4}{c}{ Airborne in situ } & \multicolumn{2}{|c}{ Airborne remote sensing } \\
\hline Height $(\mathrm{km})$ & $\begin{array}{l}\text { Scattering } \\
\text { coefficient } \\
\text { at } 450 \mathrm{~nm} \\
\left(\mathrm{~km}^{-1}\right)\end{array}$ & $\begin{array}{l}\text { Scattering } \\
\text { coefficient } \\
\text { at } 550 \mathrm{~nm} \\
\left(\mathrm{~km}^{-1}\right)\end{array}$ & $\begin{array}{l}\text { Scattering } \\
\text { coefficient } \\
\text { at } 700 \mathrm{~nm} \\
\left(\mathrm{~km}^{-1}\right)\end{array}$ & $\begin{array}{l}\text { SSA } \\
\text { at } 550 \mathrm{~nm}\end{array}$ & $\begin{array}{l}\text { Backscatter } \\
\text { coefficient } \\
\text { at } 355 \mathrm{~nm} \\
\left(\mathrm{~km}^{-1}\right)\end{array}$ & $\begin{array}{l}\text { Extinction } \\
\text { coefficient } \\
\text { at } 355 \mathrm{~nm} \\
\left(\mathrm{~km}^{-1}\right)\end{array}$ \\
\hline 3.2 & $0.076 \pm 0.002$ & $0.054 \pm 0.002$ & $0.032 \pm 0.002$ & $0.95 \pm 0.01$ & 0.004 & 0.310 \\
& $\mathbf{0 . 0 7 4}$ & $\mathbf{0 . 0 5 4}$ & $\mathbf{0 . 0 3 4}$ & $\mathbf{0 . 9 5}$ & $\mathbf{0 . 0 0 4}$ & $\mathbf{0 . 3 0 7}$ \\
\hline 2.7 & $0.082 \pm 0.004$ & $0.055 \pm 0.003$ & $0.033 \pm 0.002$ & $0.91 \pm 0.01$ & 0.002 & 0.192 \\
& $\mathbf{0 . 0 8 0}$ & $\mathbf{0 . 0 5 6}$ & $\mathbf{0 . 0 3 3}$ & $\mathbf{0 . 9 1}$ & $\mathbf{0 . 0 0 2}$ & $\mathbf{0 . 2 0 0}$ \\
\hline 1.8 & $0.071 \pm 0.004$ & $0.051 \pm 0.002$ & $0.031 \pm 0.002$ & $0.90 \pm 0.01$ & 0.001 & 0.099 \\
& $\mathbf{0 . 0 7 0}$ & $\mathbf{0 . 0 5 1}$ & $\mathbf{0 . 0 3 1}$ & $\mathbf{0 . 9 0}$ & $\mathbf{0 . 0 0 1}$ & $\mathbf{0 . 1 0 8}$ \\
\hline
\end{tabular}

Table D2. As for Table D1, for the retrieval above ocean.

\begin{tabular}{|c|c|c|c|c|c|c|}
\hline \multirow[b]{2}{*}{ Height $(\mathrm{km})$} & \multicolumn{4}{|c|}{ Airborne in situ } & \multicolumn{2}{|c|}{ Airborne remote sensing } \\
\hline & $\begin{array}{l}\text { Scattering } \\
\text { coefficient } \\
\text { at } 450 \mathrm{~nm} \\
\left(\mathrm{~km}^{-1}\right)\end{array}$ & $\begin{array}{l}\text { Scattering } \\
\text { coefficient } \\
\text { at } 550 \mathrm{~nm} \\
\left(\mathrm{~km}^{-1}\right)\end{array}$ & $\begin{array}{l}\text { Scattering } \\
\text { coefficient } \\
\text { at } 700 \mathrm{~nm} \\
\left(\mathrm{~km}^{-1}\right)\end{array}$ & $\begin{array}{l}\text { SSA } \\
\text { at } 550 \mathrm{~nm}\end{array}$ & $\begin{array}{l}\text { Backscatter } \\
\text { coefficient } \\
\text { at } 355 \mathrm{~nm} \\
\left(\mathrm{~km}^{-1}\right)\end{array}$ & $\begin{array}{l}\text { Extinction } \\
\text { coefficient } \\
\text { at } 355 \mathrm{~nm} \\
\left(\mathrm{~km}^{-1}\right)\end{array}$ \\
\hline 3.2 & $\begin{array}{l}0.070 \pm 0.011 \\
\mathbf{0 . 0 7 2}\end{array}$ & $\begin{array}{l}0.049 \pm 0.008 \\
\mathbf{0 . 0 5 3}\end{array}$ & $\begin{array}{l}0.030 \pm 0.005 \\
\mathbf{0 . 0 3 3}\end{array}$ & $\begin{array}{l}0.93 \pm 0.03 \\
\mathbf{0 . 9 4}\end{array}$ & $\begin{array}{l}0.003 \\
\mathbf{0 . 0 0 3}\end{array}$ & $\begin{array}{l}0.151 \\
\mathbf{0 . 1 4 4}\end{array}$ \\
\hline 2.7 & $\begin{array}{l}0.070 \pm 0.017 \\
\mathbf{0 . 0 7 7}\end{array}$ & $\begin{array}{l}0.050 \pm 0.012 \\
\mathbf{0 . 0 5 6}\end{array}$ & $\begin{array}{l}0.030 \pm 0.008 \\
\mathbf{0 . 0 3 5}\end{array}$ & $\begin{array}{l}0.91 \pm 0.02 \\
\mathbf{0 . 9 2}\end{array}$ & $\begin{array}{l}0.002 \\
\mathbf{0 . 0 0 2}\end{array}$ & $\begin{array}{l}0.111 \\
\mathbf{0 . 1 2 1}\end{array}$ \\
\hline 2.1 & $\begin{array}{l}0.083 \pm 0.007 \\
\mathbf{0 . 0 8 9}\end{array}$ & $\begin{array}{l}0.060 \pm 0.005 \\
\mathbf{0 . 0 6 7}\end{array}$ & $\begin{array}{l}0.038 \pm 0.004 \\
\mathbf{0 . 0 4 4}\end{array}$ & $\begin{array}{l}0.91 \pm 0.01 \\
\mathbf{0 . 9 2}\end{array}$ & $\begin{array}{l}0.003 \\
\mathbf{0 . 0 0 2}\end{array}$ & $\begin{array}{l}0.155 \\
\mathbf{0 . 1 5 3}\end{array}$ \\
\hline 1.3 & $\begin{array}{l}0.116 \pm 0.005 \\
\mathbf{0 . 1 1 0}\end{array}$ & $\begin{array}{l}0.085 \pm 0.004 \\
\mathbf{0 . 0 8 6}\end{array}$ & $\begin{array}{l}0.053 \pm 0.003 \\
\mathbf{0 . 0 5 8}\end{array}$ & $\begin{array}{l}0.92 \pm 0.01 \\
\mathbf{0 . 9 3}\end{array}$ & $\begin{array}{l}0.001 \\
\mathbf{0 . 0 0 2}\end{array}$ & $\begin{array}{l}0.089 \\
\mathbf{0 . 1 6 8}\end{array}$ \\
\hline
\end{tabular}


Competing interests. The authors declare that they have no conflict of interest.

Acknowledgements. The research leading to these results received funding from the European Union's Seventh Framework Programme (FP7/2007-2013) under grant agreement no. 227159 (EUFAR: European Facility for Airborne Research in Environmental and Geo-sciences) and the UK Natural Environment Research Council (grant ref. NE/E018092/1). Airborne data were obtained using the BAe-146-301 atmospheric research aircraft (ARA) flown by Directflight Ltd and managed by the Facility for Airborne Atmospheric Measurements (FAAM), which is a joint entity of the Natural Environment Research Council (NERC) and the Met Office. This research has received funding from the European Union's Horizon 2020 research and innovation programme under grant agreement no. 654109. The publication was supported by the European Union's Seventh Framework Programme (FP7-REGPOT2012-2013-1), in the framework of the project BEYOND, under grant agreement no. 316210 (BEYOND - Building Capacity for a Centre of Excellence for EO-based monitoring of Natural Disasters). Athanasios Nenes acknowledges support from a Georgia Power Faculty Scholar Chair and a Cullen-Peck Faculty Fellowship.

We thank the ICARE Data and Services Center and the NASA Langley Research Center for providing access to the data used in this study. The authors would also like to acknowledge the contribution of Jim Haywood, Alan Vance and Kate Turnbull from the UK Met Office, Jason Tackett from the CALIPSO Lidar Science Working Group at NASA Langley Research Center and Ioannis Binietoglou from IAASARS, National Observatory of Athens.

Edited by: P. Herckes

Reviewed by: three anonymous referees

\section{References}

Allan, J. D., Jimenez, J. L., Williams, P. I., Alfarra, M. R., Bower, K. N., Jayne, J. T., Coe, H., and Worsnop, D. R.: Quantitative sampling using an Aerodyne Aerosol Mass Spectrometer. Part 1: Techniques of data interpretation and error analysis, J. Geophys. Res.-Atmos., 108, 4090, doi:10.1029/2002JD002358, 2003.

Allen, G., Illingworth, S. M., O'Shea, S. J., Newman, S., Vance, A., Bauguitte, S. J.-B., Marenco, F., Kent, J., Bower, K., Gallagher, M. W., Muller, J., Percival, C. J., Harlow, C., Lee, J., and Taylor, J. P.: Atmospheric composition and thermodynamic retrievals from the ARIES airborne TIR-FTS system - Part 2: Validation and results from aircraft campaigns, Atmos. Meas. Tech., 7, 4401-4416, doi:10.5194/amt-7-4401-2014, 2014.

Anderson, T. L. and Ogren, J. A.: Determining aerosol radiative properties using the TSI 3563 integrating nephelometer, Aerosol Sci. Technol., 29, 57-69, 1998.

Athanasopoulou, E., Protonotariou, A. P., Bossioli, E., Dandou, A., Tombrou, M., Allan, J. D., Coe, H., Mihalopoulos, N., Kalogiros, J., Bacak, A., Sciare, J., and Biskos, G.: Aerosol chemistry above an extended archipelago of the eastern Mediterranean basin during strong northern winds, Atmos. Chem. Phys., 15, 8401-8421, doi:10.5194/acp-15-8401-2015, 2015.
Belyaev, S. P. and Levin, L. M.: Investigation of aerosol aspiration by photographing particle tracks under flash illumination, J. Aerosol Sci., 3, 127-140, 1972.

Bezantakos, S., Barmpounis, K., Giamarelou, M., Bossioli, E., Tombrou, M., Mihalopoulos, N., Eleftheriadis, K., Kalogiros, J., D. Allan, J., Bacak, A., Percival, C. J., Coe, H., and Biskos, G.: Chemical composition and hygroscopic properties of aerosol particles over the Aegean Sea, Atmos. Chem. Phys., 13, 1159511608, doi:10.5194/acp-13-11595-2013, 2013.

Bohren, C. F. and Huffman, D. R.: Absorption and Scattering of Light by Small Particles, John Wiley \& Sons, Inc., New York, ISBN-13: 9780471057727, 1983.

Bond, T. C., Anderson, T. L., and Campbell, D.: Calibration and intercomparison of filter-based measurements of visible light absorption by aerosols, Aerosol Sci. Technol., 30, 582-600, doi:10.1080/027868299304435, 1999.

Bougiatioti, A., Fountoukis, C., Kalivitis, N., Pandis, S. N., Nenes, A., and Mihalopoulos, N.: Cloud condensation nuclei measurements in the marine boundary layer of the Eastern Mediterranean: $\mathrm{CCN}$ closure and droplet growth kinetics, Atmos. Chem. Phys., 9, 7053-7066, doi:10.5194/acp-9-7053-2009, 2009.

Bougiatioti, A., Nenes, A., Fountoukis, C., Kalivitis, N., Pandis, S. N., and Mihalopoulos, N.: Size-resolved CCN distributions and activation kinetics of aged continental and marine aerosol, Atmos. Chem. Phys., 11, 8791-8808, doi:10.5194/acp-11-87912011, 2011.

Bougiatioti, A., Bezantakos, S., Stavroulas, I., Kalivitis, N., Kokkalis, P., Biskos, G., Mihalopoulos, N., Papayannis, A., and Nenes, A.: Biomass-burning impact on CCN number, hygroscopicity and cloud formation during summertime in the eastern Mediterranean, Atmos. Chem. Phys., 16, 7389-7409, doi:10.5194/acp-16-7389-2016, 2016.

Brioude, J., Arnold, D., Stohl, A., Cassiani, M., Morton, D., Seibert, P., Angevine, W., Evan, S., Dingwell, A., Fast, J. D., Easter, R. C., Pisso, I., Burkhart, J., and Wotawa, G.: The Lagrangian particle dispersion model FLEXPART-WRF version 3.1, Geosci. Model Dev., 6, 1889-1904, doi:10.5194/gmd-61889-2013, 2013.

Burton, S. P., Ferrare, R. A., Vaughan, M. A., Omar, A. H., Rogers, R. R., Hostetler, C. A., and Hair, J. W.: Aerosol classification from airborne HSRL and comparisons with the CALIPSO vertical feature mask, Atmos. Meas. Tech., 6, 13971412, doi:10.5194/amt-6-1397-2013, 2013.

CALIPSO Science Team: CALIPSO/CALIOP Level 1B, Lidar Profile Data, version 3.01, Hampton, VA, USA: NASA Atmospheric Science Data Center (ASDC), available at: doi:10.5067/CALIOP/CALIPSO/CAL_LID_L1-ValStage1-V301_L1B-003.01 (last access: 5 December 2016), 2015a.

CALIPSO Science Team: CALIPSO/CALIOP Level 2, Lidar Aerosol Layer Data, version 3.01, Hampton, VA, USA: NASA Atmospheric Science Data Center (ASDC), available at: doi:10.5067/CALIOP/CALIPSO/CAL_LID_L2_05kmAProProv-V3-01_L2-003.01 (last access: 5 December 2016), 2015 b.

Chaikovsky, A., Dubovik, O., Holben, B., Bril, A., Goloub, P., Tanré, D., Pappalardo, G., Wandinger, U., Chaikovskaya, L., Denisov, S., Grudo, J., Lopatin, A., Karol, Y., Lapyonok, T., Amiridis, V., Ansmann, A., Apituley, A., Allados-Arboledas, L., Binietoglou, I., Boselli, A., D’Amico, G., Freudenthaler, V., Giles, D., Granados-Muñoz, M. J., Kokkalis, P., Nicolae, D., Os- 
hchepkov, S., Papayannis, A., Perrone, M. R., Pietruczuk, A., Rocadenbosch, F., Sicard, M., Slutsker, I., Talianu, C., De Tomasi, F., Tsekeri, A., Wagner, J., and Wang, X.: Lidar-Radiometer Inversion Code (LIRIC) for the retrieval of vertical aerosol properties from combined lidar/radiometer data: development and distribution in EARLINET, Atmos. Meas. Tech., 9, 1181-1205, doi:10.5194/amt-9-1181-2016, 2016.

Chang, R. Y.-W., Slowik, J. G., Shantz, N. C., Vlasenko, A., Liggio, J., Sjostedt, S. J., Leaitch, W. R., and Abbatt, J. P. D.: The hygroscopicity parameter $(\kappa)$ of ambient organic aerosol at a field site subject to biogenic and anthropogenic influences: relationship to degree of aerosol oxidation, Atmos. Chem. Phys., 10, 5047-5064, doi:10.5194/acp-10-5047-2010, 2010.

Chazette, P., Bocquet, M., Royer, P., Winiarek, V., Raut, J. -C., Labazuy, P., Gouhier, M., Lardier, M., and Cariou, J. -P.: Eyjafjallajökull ash concentrations derived from both lidar and modeling, J. Geophys. Res., 117, D00U14, doi:10.1029/2011JD015755, 2012.

Coleman, T. F. and Li, Y.: On the Convergence of Reflective Newton Methods for Large-Scale Nonlinear Minimization Subject to Bounds, Math. Program., 67, 189-224, 1994.

Coleman, T. F. and Li, Y.: An Interior, Trust Region Approach for Nonlinear Minimization Subject to Bounds, SIAM J. Optimiz., 6, 418-445, 1996.

Dinar, E., Mentel, T. F., and Rudich, Y.: The density of humic acids and humic like substances (HULIS) from fresh and aged wood burning and pollution aerosol particles, Atmos. Chem. Phys., 6, 5213-5224, doi:10.5194/acp-6-5213-2006, 2006.

Dinar, E., Riziq, A. A., Spindler, C., Erlick, C., Kiss, G., and Rudich, Y.: The complex refractive index of atmospheric and model humic-like substances (HULIS) retrieved by a cavity ring down aerosol spectrometer (CRD-AS), Faraday Discuss., 137, 279-295, 2008.

Dubovik, O.: Optimization of Numerical Inversion in Photopolarimetric Remote Sensing, in: Photopolarimetry in Remote Sensing, edited by: Videen, G., Yatskiv, Y., and Mishchenko, M., Kluwer Academic Publishers, Dordrecht, the Netherlands, 65106, 2004.

Dubovik, O. and King, M.: A flexible inversion algorithm for retrieval of aerosol optical properties from Sun and sky radiance measurements, J. Geophys. Res., 105, 20673-20696, doi:10.1029/2000JD900282, 2000.

Dubovik, O., Sinyuk, A., Lapyonok, T., Holben, B. N., Mishchenko, M., Yang, P., Eck, T. F., Volten, H., Munoz, O., Veihelmann, B., van der Zande, W. J., Leon, J.-F., Sorokin, M., and Slutsker, I.: Application of spheroid models to account for aerosol particle nonsphericity in remote sensing of desert dust, J. Geophys. Res., 111, D11208, doi:10.1029/2005JD006619, 2006.

Dubovik, O., Holben, B., Eck, T. F., Smirnov, A., Kaufman, Y. J., King, M. D., Tanré, D., and Slutsker, I.: Variability of Absorption and Optical Properties of Key Aerosol Types Observed in Worldwide Locations, J. Atmos. Sci., 59, 590-608, doi:10.1175/15200469(2002)059<0590:VOAAOP>2.0.CO;2, 2002.

Engelhart, G. J., Hildebrandt, L., Kostenidou, E., Mihalopoulos, N., Donahue, N. M., and Pandis, S. N.: Water content of aged aerosol, Atmos. Chem. Phys., 11, 911-920, doi:10.5194/acp-11911-2011, 2011.

Ervens, B., Turpin, B. J., and Weber, R. J.: Secondary organic aerosol formation in cloud droplets and aqueous parti- cles (aqSOA): a review of laboratory, field and model studies, Atmos. Chem. Phys., 11, 11069-11102, doi:10.5194/acp-1111069-2011, 2011.

FAAM: Facility for Airborne Atmospheric Measurements, Natural Environment Research Council, Met Office, 2014, FAAM B638 ACEMED and EUFAR flight: Airborne atmospheric measurements from core and non-core instrument suites on board the BAE-146 aircraft, NCAS British Atmospheric Data Centre, available at: http://catalogue.ceda.ac.uk/uuid/ f014fe1ff19f40d78c83223458d82aee, last access: 5 December 2016.

Fleming, R. J. and May, R. D.: The 2nd Generation Water Vapor Sensing System and Benefits of Its Use on Commercial Air craft for Air Carriers and Society, UCAR, Boulder, CO, available at: https://www.eol.ucar.edu/system/files/spectrasensors.pdf (last access: 16 December 2014), 2004.

Fountoukis, C. and Nenes, A.: ISORROPIA II: a computationally efficient thermodynamic equilibrium model for $\mathrm{K}^{+}-$ $\mathrm{Ca}^{2+}-\mathrm{Mg}^{2+}-\mathrm{NH}_{4}^{+}-\mathrm{Na}^{+}-\mathrm{SO}_{4}^{2-}-\mathrm{NO}_{3}^{-}-\mathrm{Cl}^{-}-\mathrm{H}_{2} \mathrm{O}$ aerosols, Atmos. Chem. Phys., 7, 4639-4659, doi:10.5194/acp-7-4639-2007, 2007.

Fountoukis, C., Nenes, A., Sullivan, A., Weber, R., Van Reken, T., Fischer, M., Matías, E., Moya, M., Farmer, D., and Cohen, R. C.: Thermodynamic characterization of Mexico City aerosol during MILAGRO 2006, Atmos. Chem. Phys., 9, 2141-2156, doi:10.5194/acp-9-2141-2009, 2009.

Gasteiger, J., Wiegner, M., Groß, S., Freudenthaler, V., Toledano, C., Tesche, M., and Kandler, K.: Modelling lidar-relevant optical properties of complex mineral dust aerosols, Tellus B, 63, 725741, doi:10.1111/j.1600-0889.2011.00559.x,2011.

Gerbig, C., Schmitgen, S., Kley, D., and Volz-Thomas, A.: An improved fast-response vacuum UV resonance fluorescence $\mathrm{CO}$ instrument, J. Geophys. Res., 104, 1699-1704, 1999.

Guo, H., Xu, L., Bougiatioti, A., Cerully, K. M., Capps, S. L., Hite Jr., J. R., Carlton, A. G., Lee, S.-H., Bergin, M. H., Ng, N. L., Nenes, A., and Weber, R. J.: Fine-particle water and $\mathrm{pH}$ in the southeastern United States, Atmos. Chem. Phys., 15, 5211-5228, doi:10.5194/acp-15-5211-2015, 2015.

Guo, H., Sullivan, A. P., Campuzano-Jost, P., Schroder, J. C., LopezHilfiger, F. D., Dibb, J. E., Jimenez, J. L., Thornton, J. A, Brown, S. S., Nenes, A., and Weber, R. J.: Fine particle pH and the partitioning of nitric acid during winter in the northeastern United States, J. Geophys. Res.-Atmos., 121, 10355-10376, doi:10.1002/2016JD025311, 2016.

Haywood, J., Francis, P., Dubovik, O., Glew, M., and Holben, B.: Comparison of aerosol size distributions, radiative properties, and optical depths determined by aircraft observations and Sun photometers during SAFARI 2000, J.Geophys. Res., 108, 8471, doi:10.1029/2002JD002250, 2003.

Hegg, D. A., Livingston, J., Hobbs, P. V., Novakov, T., and Russell, P.: Chemical apportionment of aerosol column optical depth off the mid-Atlantic coast of the United States, J. Geophys. Res.Atmos., 102, 25293-25303, 1997.

Heim, M., Mullins, J. M., Umhauer, H., and Kasper, G.: Performance evaluation of three optical particle counters with an efficient "multimodal" calibration method, J. Aerosol Sci., 39, 1019-1031, 2008.

Hennigan, C. J., Izumi, J., Sullivan, A. P., Weber, R. J., and Nenes, A.: A critical evaluation of proxy methods used to estimate the 
acidity of atmospheric particles, Atmos. Chem. Phys., 15, 27752790, doi:10.5194/acp-15-2775-2015, 2015.

Highwood, E. J., Northway, M. J., McMeeking, G. R., Morgan, W. T., Liu, D., Osborne, S., Bower, K., Coe, H., Ryder, C., and Williams, P.: Aerosol scattering and absorption during the EUCAARI-LONGREX flights of the Facility for Airborne Atmospheric Measurements (FAAM) BAe-146: can measurements and models agree?, Atmos. Chem. Phys., 12, 7251-7267, doi:10.5194/acp-12-7251-2012, 2012.

Holben, B. N., Eck, T. F., Slutsker, I., Tanré, D., Buis, J. P., Setzer, A., Vermote, E., Reagan, J. A., Kaufman, Y. J., Nakajima, T., Lavenu, F., Jankowiak, I., and Smirnov, A.: AERONET - A federated instrument network and data archive for aerosol characterization, Remote Sens. Environ., 66, 1-16, 1998.

ICARE Data Center: CALIPSO data, available at: http://www.icare. univ-lille1.fr/, last access: 5 December 2016.

IPCC: Climate Change 2013: The Physical Science Basis. Contribution of Working Group I to the Fifth Assessment Report of the Intergovernmental Panel on Climate Change, Cambridge University Press, Cambridge, United Kingdom and New York, NY, USA, 1535 pp., 2013.

Johnson, B. T., Haywood, J. M., Langridge, J. M., Darbyshire, E., Morgan, W. T., Szpek, K., Brooke, J., Marenco, F., Coe, H., Artaxo, P., Longo, K. M., Mulcahy, J., Mann, G., Dalvi, M., and Bellouin, N.: Evaluation of biomass burning aerosols in the HadGEM3 climate model with observations from the SAMBBA field campaign, Atmos. Chem. Phys. Discuss., doi:10.5194/acp2016-442, in review, 2016.

Kalkavouras, P., Bossioli, E., Bezantakos, S., Bougiatioti, A., Kalivitis, N., Stavroulas, I., Kouvarakis, G., Protonotariou, A. P., Dandou, A., Biskos, G., Mihalopoulos, N., Nenes, A., and Tombrou, M.: New Particle Formation in the South Aegean Sea during the Etesians: importance for $\mathrm{CCN}$ production and cloud droplet number, Atmos. Chem. Phys. Discuss., doi:10.5194/acp2016-330, in review, 2016.

Kanitz, T., Ansmann, A., Foth, A., Seifert, P., Wandinger, U., Engelmann, R., Baars, H., Althausen, D., Casiccia, C., and Zamorano, F.: Surface matters: limitations of CALIPSO V3 aerosol typing in coastal regions, Atmos. Meas. Tech., 7, 2061-2072, doi:10.5194/amt-7-2061-2014, 2014.

Klett, D.: Lidar inversion with variable backscatter/extinction ratios, Appl. Optics, 31, 1638-1643, 1985.

Le Breton, M., Bacak, A., Muller, J. B. A., O’Shea, S. J., Xiao, P., Ashfold, M. N. R., Cooke, M. C., Batt, R., Shallcross, D. E., Oram, D. E., Forster, G., Bauguitte, S. J.-B., Palmer, P. I., Parrington, M., Lewis, A. C., Lee, J. D., and Percival, C. J.: Airborne hydrogen cyanide measurements using a chemical ionisation mass spectrometer for the plume identification of biomass burning forest fires, Atmos. Chem. Phys., 13, 92179232, doi:10.5194/acp-13-9217-2013, 2013.

Lelieveld, J., Berresheim, H., Borrmann, S., Crutzen, P. J., Dentener, F. J., Fischer, H., Feichter, J., Flatau, P. J., Heland, J., Holzinger, R., Korrmann, R., Lawrence, M. G., Levin, Z., Markowicz, K. M., Mihalopoulos, N., Minikin, A., Ramanathan, V., de Reus, M., Roelofs, G. J., Scheeren, H. A., Sciare, J., Schlager, H., Schultz, M., Siegmund, P., Steil, B., Stephanou, E. G., Stier, P., Traub, M., Warneke, C., Williams, J., and Ziereis, H.: Global Air Pollution Crossroads over the Mediterranean, Science, 298, 794-799, 2002.
Liao, H. and Seinfeld J. H.: Global impacts of gas-phase chemistryaerosol interactions on direct radiative forcing by anthropogenic aerosols and ozone, J. Geophys. Res., 110, D18208, doi:10.1029/2005JD005907, 2005.

Lobert, J. M., Scharffe, D. H., Hao, W. M., and Crutzen, P. J.: Importance of biomass burning in the atmospheric budgets of nitrogen containing gases, Nature, 346, 552-554, 1990.

Lopatin, A., Dubovik, O., Chaikovsky, A., Goloub, P., Lapyonok, T., Tanré, D., and Litvinov, P.: Enhancement of aerosol characterization using synergy of lidar and sun-photometer coincident observations: the GARRLiC algorithm, Atmos. Meas. Tech., 6, 2065-2088, doi:10.5194/amt-6-2065-2013, 2013.

Lowe, P. R. and Ficke, J. M.: The computation of saturation vapor pressure. Tech. Paper No. 4-74, Environmental Prediction Research Facility, Naval Postgraduate School, Monterey, CA, 27 pp., 1974.

Malm, K. C. and Day, D. E.: Estimates of aerosol species scattering characteristics as a function of relative humidity, Atmos. Environ., 35, 2845-2860, 2001.

Marenco, F., Johnson, B., Turnbull, K., Newman, S., Haywood, J., Webster, H., and Ricketts, H.: Airborne Lidar Observations of the 2010 Eyjafjallajökull Volcanic Ash Plume, J. Geophys. Res., 116, D00U05, doi:10.1029/2011JD016396, 2011.

McConnell, C. L., Formenti, P., Highwood, E. J., and Harrison, M. A. J.: Using aircraft measurements to determine the refractive index of Saharan dust during the DODO Experiments, Atmos. Chem. Phys., 10, 3081-3098, doi:10.5194/acp-10-30812010, 2010.

Mie, G.: Beiträge zur Optik trüber Medien, speziell kolloidaler Metallösungen, Ann. Phys.-Berlin, Vierte Folge, 25, 77-445, 1908.

Mishchenko, M. I. and Travis, L. D.: Satellite retrieval of aerosol properties over the ocean using polarization as well as intensity of reflected sunlight, J. Geophys. Res., 102, 16989-17013, 1997.

Mikhailov, E., Vlasenko, S., Rose, D., and Pöschl, U.: Mass-based hygroscopicity parameter interaction model and measurement of atmospheric aerosol water uptake, Atmos. Chem. Phys., 13, 717740, doi:10.5194/acp-13-717-2013, 2013.

Morgan, W. T., Allan, J. D., Bower, K. N., Highwood, E. J., Liu, D., McMeeking, G. R., Northway, M. J., Williams, P. I., Krejci, R., and Coe, H.: Airborne measurements of the spatial distribution of aerosol chemical composition across Europe and evolution of the organic fraction, Atmos. Chem. Phys., 10, 4065-4083, doi:10.5194/acp-10-4065-2010, 2010.

Müller, D., Böckmann, C., Kolgotin, A., Schneidenbach, L., Chemyakin, E., Rosemann, J., Znak, P., and Romanov, A.: Microphysical particle properties derived from inversion algorithms developed in the framework of EARLINET, Atmos. Meas. Tech., 9, 5007-5035, doi:10.5194/amt-9-5007-2016, 2016.

NASA FIRMS: The MODIS Active Fire Detections, MCD14ML, available at: https://earthdata.nasa.gov/active-fire-data, last access: 5 December 2016.

NOAA/OAR/ESRL PSD: Sea surface temperature (SST) data, Boulder, Colorado, USA, available at: http://www.esrl.noaa.gov/ psd//, last access: 5 December 2016.

NCEP FNL: Operational Model Global Tropospheric Analyses, Research Data Archive at the National Center for Atmospheric Research, Computational and Information Systems Laboratory, available at: https://doi.org/10.5065/D6FB50XD (last access: 5 December 2016), 1997. 
Nenes, A., Pandis, S. N., and Pilinis, C.: ISORROPIA: A new thermodynamic equilibrium model for multiphase multicomponent inorganic aerosols, Aquat. Geoch., 4, 123-152, 1998a.

Nenes, A., Pilinis, C., and Pandis, S. N.: Continued Development and Testing of a New Thermodynamic Aerosol Module for Urban and Regional Air Quality Models, Atmos. Environ., 33, 1553-1560, 1998b.

Omar, A. H., Won, J. -G., Winker, D. M., Yoon, S. -C., Dubovik, O., and McCormick, M. P.: Development of global aerosol models using cluster analysis of Aerosol Robotic Network (AERONET) measurements, J. Geophys. Res., 110, D10S14, doi:10.1029/2004JD004874, 2005.

Omar, A. H., Winker, D. M., Vaughan, M. A., Hu, Y., Trepte, C. R., Ferrare, R. A., Lee, K. -P., Hostetler, C. A., Kittaka, C., Rogers, R. R., Kuehn, R. E., and Liu, Z.: The CALIPSO Automated Aerosol Classification and Lidar Ratio Selection Algorithm, J. Atmos. Ocean. Tech., 26, 1994-2014, doi:10.1175/2009JTECHA1231.1, 2009.

Ogren, J. A.: Comment on "Calibration and Intercomparison of Filter-Based Measurements of Visible Light Absorption by Aerosols", Aerosol Sci. Technol., 44, 589-591, doi:10.1080/02786826.2010.482111, 2010.

Petters, M. D. and Kreidenweis, S. M.: A single parameter representation of hygroscopic growth and cloud condensation nucleus activity, Atmos. Chem. Phys., 7, 1961-1971, doi:10.5194/acp-71961-2007, 2007.

Pikridas, M., Riipinen, I., Hildebrandt, L., Kostenidou, E., Manninen, H., Mihalopoulos, N., Kalivitis, N., Burkhart, J. F., Stohl, A., Kulmala, M., and Pandis, S. N.: New particle formation at a remote site in the eastern Mediterranean, J. Geophys. Res., 117, D12205, doi:10.1029/2012JD017570, 2012.

Pilinis, C., Pandis, S. N., and Seinfeld J. H.: Sensitivity of direct climate forcing by atmospheric aerosols to aerosol size and composition, J. Geophys. Res., 100, 18739-18754, doi:10.1029/95JD02119, 1995.

Quinn, P. K., Bates, T. S., Baynard, T., Clarke, A. D., Onasch, T. B., Wang, W., Rood, M. J., Andrews, E., Allan, J., Carrico, C. M., Coffman, D., and Worsnop, D.: Impact of particulate organic matter on the relative humidity dependence of light scattering: A simplified parameterization, Geophys. Res. Lett., 32, L22809, doi:10.1029/2005GL024322, 2005.

Rodgers, C.: Inverse Methods for Atmospheric Sounding: Theory and Practice, World Scientific, Singapore, ISBN-13: 978-981-022740-1, 2000.

Rosenberg, P. D., Dean, A. R., Williams, P. I., Dorsey, J. R., Minikin, A., Pickering, M. A., and Petzold, A.: Particle sizing calibration with refractive index correction for light scattering optical particle counters and impacts upon PCASP and CDP data collected during the Fennec campaign, Atmos. Meas. Tech., 5, 1147-1163, doi:10.5194/amt-5-1147-2012, 2012.

Ryder, C. L., Highwood, E. J., Rosenberg, P. D., Trembath, J., Brooke, J. K., Bart, M., Dean, A., Crosier, J., Dorsey, J., Brindley, H., Banks, J., Marsham, J. H., McQuaid, J. B., Sodemann, H., and Washington, R.: Optical properties of Saharan dust aerosol and contribution from the coarse mode as measured during the Fennec 2011 aircraft campaign, Atmos. Chem. Phys., 13, 303325, doi:10.5194/acp-13-303-2013, 2013.

Seinfeld, J. H. and Pandis, S. N.: Atmospheric Chemistry and Physics: from Air Pollution to Climate Change 2nd Edn., John
Wiley \& Sons, Inc., Hoboken, New Jersey, ISBN-13: 978-0-47172018-8, 2006.

Skamarock, W., Klemp, J. B., Dudhia, J., Gill, D. O., Barker, D., Duda, M. G., Huang, X.-Y., and Wang, W.: A description of the Advanced Research WRF version 3, NCAR Technical Note NCAR/TN-475+STR, doi:10.5065/D68S4MVH, 2008.

Snider, J. R. and Petters, M. D.: Optical particle counter measurement of marine aerosol hygroscopic growth, Atmos. Chem. Phys., 8, 1949-1962, doi:10.5194/acp-8-1949-2008, 2008.

Strapp, J. W., Leaitch, W. R., and Liu, P. S. K.: Hydrated and dried aerosol-size distribution measurements from the particle measuring systems FSSP-300 probe and the deiced PSASP-100X probe, J. Atmos. Ocean. Tech., 9, 548-555, 1992.

Tombrou, M., Bossioli, E., Kalogiros, J., Allan, J. D., Bacak, A., Biskos, G., Coe, H., Dandou, A., Kouvarakis, G., Mihalopoulos, N., Percival, C. J., Protonotariou, A. P., and Szabó-Takács, B.: Physical and chemical processes of air masses in the Aegean Sea during Etesians: Aegean-GAME airborne campaign, Sci. Total Environ., 506-507, 201-216, doi:10.1016/j.scitotenv.2014.10.098, 2015.

Toon, O. B., Pollack, J. B., and Khare, B. N.: The optical constants of several atmospheric aerosol species: ammonium sulphate, aluminium oxide and sodium chloride, J. Geophys. Res., 81, 57335748, 1976.

Trembath, J., Bart, M., and Brooke, J.: FAAM Technical Note: Efficiencies of modified Rosemount housings for sampling aerosol on a fast atmospheric research aircraft, Facility for Airborne Atmospheric Measurements, FAAM, Cranfield, UK, available at: http://www.faam.ac.uk/index.php/faam-documents/ science-instruments/1673-inlet-efficiency/file (last access: 28 November 2016), 2012.

Turnbull, K.: PSAP Corrections, Met Office, OBR, UK Met Office, Exeter, UK, Technical Note No. 80, available at: http://www.faam.ac.uk/index.php/faam-documents/ science-instruments/1553-psap-obr-tn80-v1-0/file (last access: 28 November 2016), 2010.

Vance, A. K., Abel, S. J., Cotton, R. J., and Woolley, A. M.: Performance of WVSS-II hygrometers on the FAAM research aircraft, Atmos. Meas. Tech., 8, 1617-1625, doi:10.5194/amt-81617-2015, 2015.

Vaughan, M., Young, S., Winker, D., Powell, K., Omar, A., Liu, Z., Hu, Y., and Hostetler, C.: Fully automated analysis of spacebased lidar data: An overview of the CALIPSO retrieval algorithms and data products, Proc. SPIE, 5575, 16-30, 2004.

Weast, R. C. (Ed.): CRC Handbook of Chemistry and Physics (67th edition), CRC press, Boca Raton, Florida, ISBN-10: 0849304679, ISBN-13: 9780849304675, 1985.

Weber, R. J., Guo, H., Russell, A. G., and Nenes, A.: High aerosol acidity despite declining atmospheric sulfate concentrations over the past 15 years, Nat. Geosci., 9, 282-285, doi:10.1038/ngeo2665, 2016.

Weinzierl, B., Petzold, A., Esselborn, M., Wirth, M., Rasp, K., Kandler, K., Schutz, L., Koepke, P., and Fiebig, M.: Airborne measurements of dust layer properties, particle size distribution and mixing state of Saharan dust during SAMUM 2006, Tellus B, 61, 96-117, doi:10.1111/j.1600-0889.2008.00392.x, 2009.

Winker, D. M., Vaughan, M. A., Omar, A., Hu, Y., Powell, K. A., Liu, Z., Hunt, W. H., and Young, S. A.: Overview of the CALIPSO Mission and CALIOP Data Pro- 
cessing Algorithms, J. Atmos. Ocean. Tech., 26, 2310-2323, doi:10.1175/2009JTECHA1281.1, 2009.

Ziemba, L. D., Thornhill, L., Ferrare, R., Barrick, J., Beyersdorf, A., Chen, G., Crumeyrolle, S., Hair, J. W., Hostetler, C., Hudgins, C., Obland, M., Rogers, R. R., Scarino, A. J., Winstead, E. L., and Anderson B. E.: Airborne observations of aerosol extinction by in situ and remote-sensing techniques: Evaluation of particle hygroscopicity, Geophys. Res. Lett., 40, 417-422, doi:10.1029/2012GL054428, 2013. 